\title{
X-HALE: A Very Flexible UAV for Nonlinear Aeroelastic Tests
}

\author{
Carlos E. S. Cesnik ${ }^{1}$, Patrick J. Senatore ${ }^{2}$, Weihua $\mathrm{Su}^{3}$, Ella M. Atkins ${ }^{4}$ \\ The University of Michigan, Ann Arbor, MI, 48109-2140 \\ Christopher M. Shearer ${ }^{5}$ \\ U.S. Air Force Institute of Technology, Wright-Patterson AFB, OH, 45433-7765 \\ and \\ Nathan A. Pitcher ${ }^{6}$ \\ U.S. Air Force Research Laboratory, Wright-Patterson AFB, OH, 45433-5543
}

\begin{abstract}
The University of Michigan has designed and is currently building an unmanned aerial vehicle, denoted X-HALE, which is aeroelastically representative of very flexible aircraft. The objective of this test bed is to collect unique data of the geometrically nonlinear aeroelastic response coupled with the flight dynamics to be used for future code validation. The aircraft will present specific aeroelastic features (e.g., coupled rigid/elastic body instability, large wing deflection during gust, etc.) that can be measured in flight. Moreover, the airframe construction choice is such that the elastic, inertial and geometric properties can be well characterized. These are requirements driven by the need of the collected data to be used to support validation of coupled nonlinear aeroelastic/flight dynamics codes.
\end{abstract}

\section{Introduction}

$\mathrm{R}$ ECENT advances in airborne sensors and communication packages have given us the opportunity to place them at high-altitudes and for long periods of time. The missions include airborne intelligence, surveillance, and reconnaissance (ISR) for the military; ${ }^{1}$ network communication nodes for the military and civilian usage; and general atmospheric research. ${ }^{2}$ Because of the mission requirements, the aircraft platforms are characterized by high-aspect-ratio wings and, if existent, slender fuselages, resulting in very flexible vehicles. Improved mission capabilities such as longer loiter times, heavier payload, greater range, etc. drive the demand for greater aerodynamic performance on those systems. Enhanced airframe performance is generally achieved through lightweight, flexible solutions. Modern high-altitude long-endurance (HALE) aircraft designs have become so lightweight and flexible that traditional (linear) design methods are no longer adequate and nonlinear aeroelastic design methods are required to characterize structural and aeroelastic designs (Ref. 20). The wings may undergo large deformations during normal operating loads, exhibiting geometrically nonlinear behavior (Fig. 1).

In the last several years, the US Air Force has been working on a new generation Intelligence, Surveillance, and Reconnaissance (ISR) platform called "Sensorcraft." These are large HALE aircraft, with wing span of approximately $60 \mathrm{~m}$. Three basic platform shapes have been considered: wing-body-tail, single-wing and joinedwing configurations ${ }^{1}$ (see Fig. 2). For high structural performance as required for long loiter times, these configurations will lead to generally very flexible aircraft. These flexibility effects may make the response of the vehicle very different from its rigid or linearized models. ${ }^{10}$ Engineering analysis on very flexible vehicles will need to include geometrically-nonlinear structural models for the primary structures in order to capture any large deformations that may appear under operational loads. In addition to large deformations, a second characteristic of very flexible aircraft will be very low frequencies of their natural structural vibration modes. Due to this, it should

\footnotetext{
${ }^{1}$ Professor (cesnik@umich.edu), Department of Aerospace Engineering, Associate Fellow, AIAA.

${ }^{2}$ Research Assistant (senatorp@umich.edu), Department of Aerospace Engineering, Member, AIAA.

${ }^{3}$ Post-doctoral Research Fellow (suw@umich.edu), Department of Aerospace Engineering, Senior Member, AIAA.

${ }^{4}$ Associate Professor (ematkins@umich.edu), Department of Aerospace Engineering, Associate Fellow, AIAA.

${ }^{5}$ Lt. Colonel, USAF (christopher.shearer@afit.edu), Dept. of Aeronautics and Astronautics, Member, AIAA.

${ }^{6}$ Captain, USAF (nathan.pitcher@wpafb.af.mil), Vehicles Directorate, RBAA.
} 
be expected a strong coupling between the structural dynamics and the rigid-body (flight dynamics) characteristics of the vehicle.
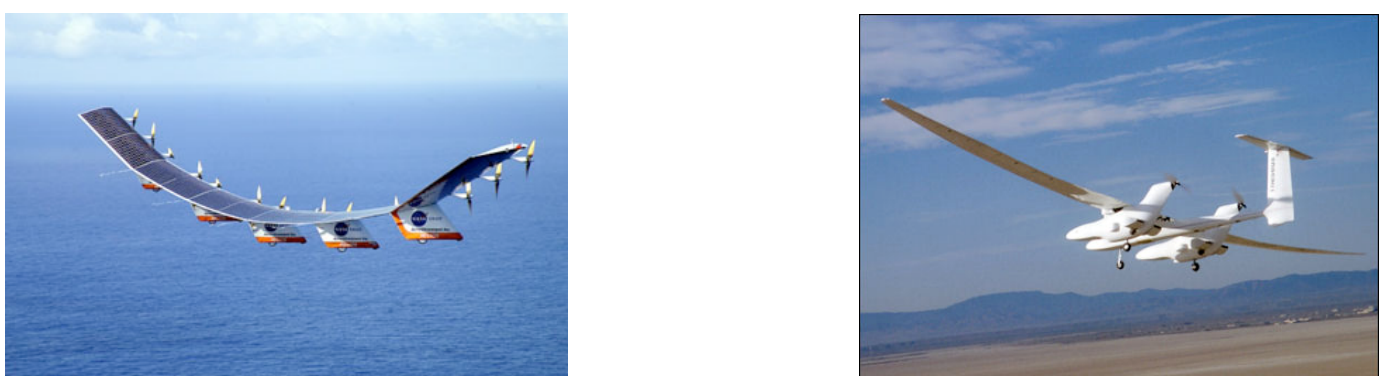

Figure 1. Aerovironment's Helios (left) and Aurora Flight Sciences' Theseus (right) showing large wing deflections (Courtesy NASA Dryden)
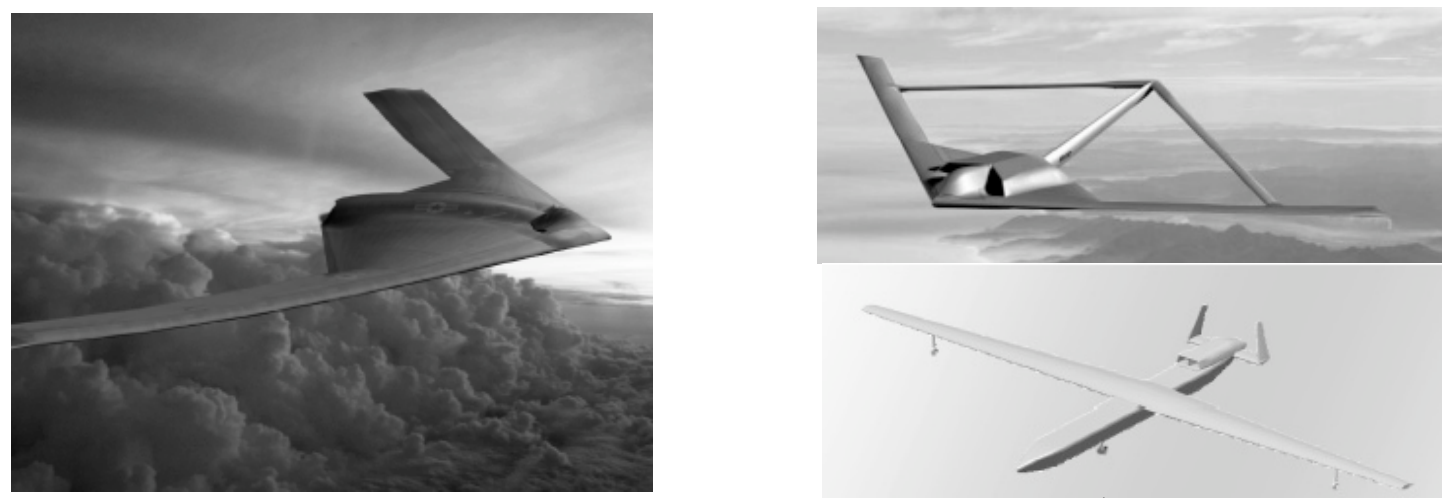

Figure 2. Three different "Sensorcraft" configurations ${ }^{1}$

More recently, Aurora Flight Sciences, Boeing Co., and Lockheed-Martin Co. have developed extreme-long duration HALE concepts ${ }^{4}$. The combination of high aerodynamic efficiency and low structural weight fraction yields inherently flexible wings and nonlinear structural and flight dynamics. HALE aircraft are expected to be susceptible to large dynamic wing deformations at low frequencies, presenting a direct impact into the flight dynamic characteristics of the vehicle, as was seen in the Helios flight tests ${ }^{3}$. On 26 June 2003, NASA's Helios aircraft ${ }^{3}$ :

HP03-2 took off at 10:06 a.m. local time from the Navy Pacific Missile Range Facility (PMRF) located on the island of Kauai, Hawaii. . . At 10:22 a.m. and 10:24 a.m., the aircraft encountered turbulence and the wing dihedral became much larger than normal and mild pitch oscillations began but quickly damped out. At about $30 \mathrm{~min}$ into the flight, the aircraft encountered turbulence and morphed into an unexpected, persistent, high dihedral configuration. As a result of the persistent high dihedral, the aircraft became unstable in a very divergent pitch mode in which the airspeed excursions from the nominal flight speed about doubled every cycle of the oscillation. The aircraft design airspeed was subsequently exceeded and the resulting high dynamic pressures caused the wing leading-edge secondary structure on the outer wing panels to fail and the solar cells and skin on the upper surface of the wing to rip off. The aircraft impacted the ocean within the confines of the PMRF test range and was destroyed... The root causes of the mishap include: [A] lack of adequate analysis methods led to an inaccurate risk assessment of the effects of configuration changes leading to an inappropriate decision to fly an aircraft configuration highly sensitive to disturbances ... [and] configuration changes to the aircraft, driven by programmatic and technological constraints, altered the aircraft from a spanloader to a highly point-loaded mass distribution on the same structure significantly reducing design robustness and margins of safety. 
The Helios accident highlighted our limited understanding and limited analytical tools necessary for designing very flexible aircraft and to potentially exploit aircraft flexibility. The number one root cause/recommendation from NASA $^{3}$ was

"[that] more advanced, multidisciplinary (structures, aeroelastic, aerodynamics, atmospheric, materials, propulsion, controls, etc.) time-domain analysis methods appropriate to highly flexible, morphing vehicles [be developed]."

Nonlinear aeroelastic solvers have been under development to improve predictions of aircraft response, stability and overall performance ${ }^{5-14}$. The body of work in the literature associated with the problem of nonlinear aeroelasticity coupled with nonlinear flight dynamics started developing at earnest in the 1990's. Without attempting to be comprehensive, what follows highlights some of the key contributions in the field, and more detailed review can be found in Refs. 10 and 11.

Early nonlinear aeroelastic work in very flexible aircraft was conducted by van Schoor and von Flotow ${ }^{25}$. Their work demonstrated the critical importance of including aircraft structural dynamics when analyzing aircraft flight dynamics of very flexible aircraft. They showed, using linearized analysis about nonlinear equilibrium points, a significant change in the classic rigid-body modes when flexible structural modeling is included. This leads to the conclusion that the coupled effects between these large deflection and vehicle flexibility and flight dynamics (e.g., roll controllability) as well as other aeroelastic effects (e.g., gust response, flutter instability) must be properly accounted for in a nonlinear aeroelastic formulation. Patil, Hodges, and Cesnik ${ }^{12}$ studied the aeroelasticity and flight dynamics of HALE aircraft. The results indicate their behavior can be significantly changed due to the large deflection of the flexible wings. Moreover, a linear aeroelastic analysis based on the undeformed geometry may lead to errors when the wings are highly flexible. That study also shows a significant difference between the short period and phugoid modes of a very flexible aircraft when comparing rigid-body, linear aeroelastic, and nonlinear aeroelastic dynamics. The short period and phugoid modes were obtained by linearizing the nonlinear dynamics about a nonlinear equilibrium. In a parallel effort, Drela ${ }^{6}$ modeled a complete flexible aircraft as an assemblage of joined nonlinear beams. In his work, the aerodynamic model was a compressible vortex/source-lattice with windaligned trailing vorticity. The nonlinear equation was solved by using a full Newton method. Through simplifications of the model, the computational size was reduced for iterative preliminary design. Jones and his coworkers ${ }^{26,27}$ have also worked on the design of HALE. In their work, they described some design challenges associated with these vehicles. From their conclusion, it is shown that standard aircraft design techniques are no longer applicable for these high-aspect-ratio wings.

Besides the work described above, Cesnik and his co-workers have developed a novel and practical solution to the coupled nonlinear aeroelasticity and flight dynamics of very flexible aircraft. Focusing on a reduced number of states to represent the complex nonlinear problem, the framework, named the University of Michigan's Nonlinear Aeroelastic Simulation Toolbox (UM/NAST), provides a suitable plant representation for control design. Several aeroelastic issues in high-altitude long-endurance aircraft have been addressed: nonlinear aeroelastic modeling, ${ }^{8,10}$ integral wing actuation for generating maneuver loads, ${ }^{22,23}$ flutter boundary enhancement ${ }^{24}$ gust load alleviation, ${ }^{21}$ and overall nonlinear vehicle optimization of unconventional configurations. ${ }^{22}$

All these numerical efforts must eventually be validated against experimental data so they can be applied to new HALE aircraft concepts. The various components of most of the existing codes have been partially validated with limited experimental data coming from bench (e.g., Refs.15-17) and/or small-scale wind tunnel tests (e.g., Refs. 18 and 19). Some of the discipline components have also been compared against well-established numerical solutions (e.g., nonlinear composite beam analyses, rigid flight dynamics, and computational fluid dynamics). However, there has been no validation of the integrated solution that brings the coupling effects between nonlinear aeroelasticity and flight dynamics, since no data is available for such exercise.

This paper describes the on-going effort to design and build a nonlinear aeroelastic test bed, named X-HALE, for test flights. The design and manufacturing of this vehicle is being conducted at the University of Michigan in collaboration with the Air Force Institute of Technology and the Air Force Research Laboratory. This will have multiple test beds from which experimental coupled nonlinear aeroelastic and flight dynamic data will be generated and made available to the community in support of the validation of nonlinear aeroelastic solvers. The following sections discuss in details the design and its expected main aeroelastic characteristics. 


\section{Systems Design, Integration, and Fabrication}

The primary purpose of X-HALE is to validate nonlinear aeroelastic and flight simulation software. To satisfy this, the systems design and layout must produce an airframe that is consistent and measurable in both real and simulated flight. This is the most unique and challenging aspect of the X-HALE concept as it complicates three of X-HALE's primary subsystems: the wing structure, electronics, and software. Structurally, the wing must be idealized and fabricated as a consistent composite beam to create a representative simulated model. To gather the required strain, control input, and flight condition data a complex array of sensors and supporting data acquisition hardware and software must be integrated without impacting the wing's structural properties. This section will describe the composition of the X-HALE airframe and the integration methods used to guarantee similar flight and simulated platforms.

\section{A. Airframe Layout}

The X-HALE is a flexible, high aspect ratio wing-boom-tail type aircraft. It has an 8-m span (constructed with eight identical $1-\mathrm{m}$ sections), $0.2-\mathrm{m}$ chord, four $0.83-\mathrm{m}$ booms with horizontal tails attached, and five motor pods with propellers, batteries, and processor boards (Fig. 3). X-HALE has a mass of $11 \mathrm{~kg}$ with an anticipated flight speed ranging from 10 to $19 \mathrm{~m} / \mathrm{s}$. Main vehicle sizing characteristics are given in

Table 1. Pitch and roll will be controlled by the horizontal elevons and yaw will be controlled using differential thrust from the motors. Disturbances will be applied with schedule all-movable horizontal tail deflections supplemented by ailerons on the dihedral outer wing sections. Those disturbances will excite wing deformation during flight, and its response will be recorded from a series of on-board sensors. Those sensors are a collection of IMU, strain gages, and accelerometers.

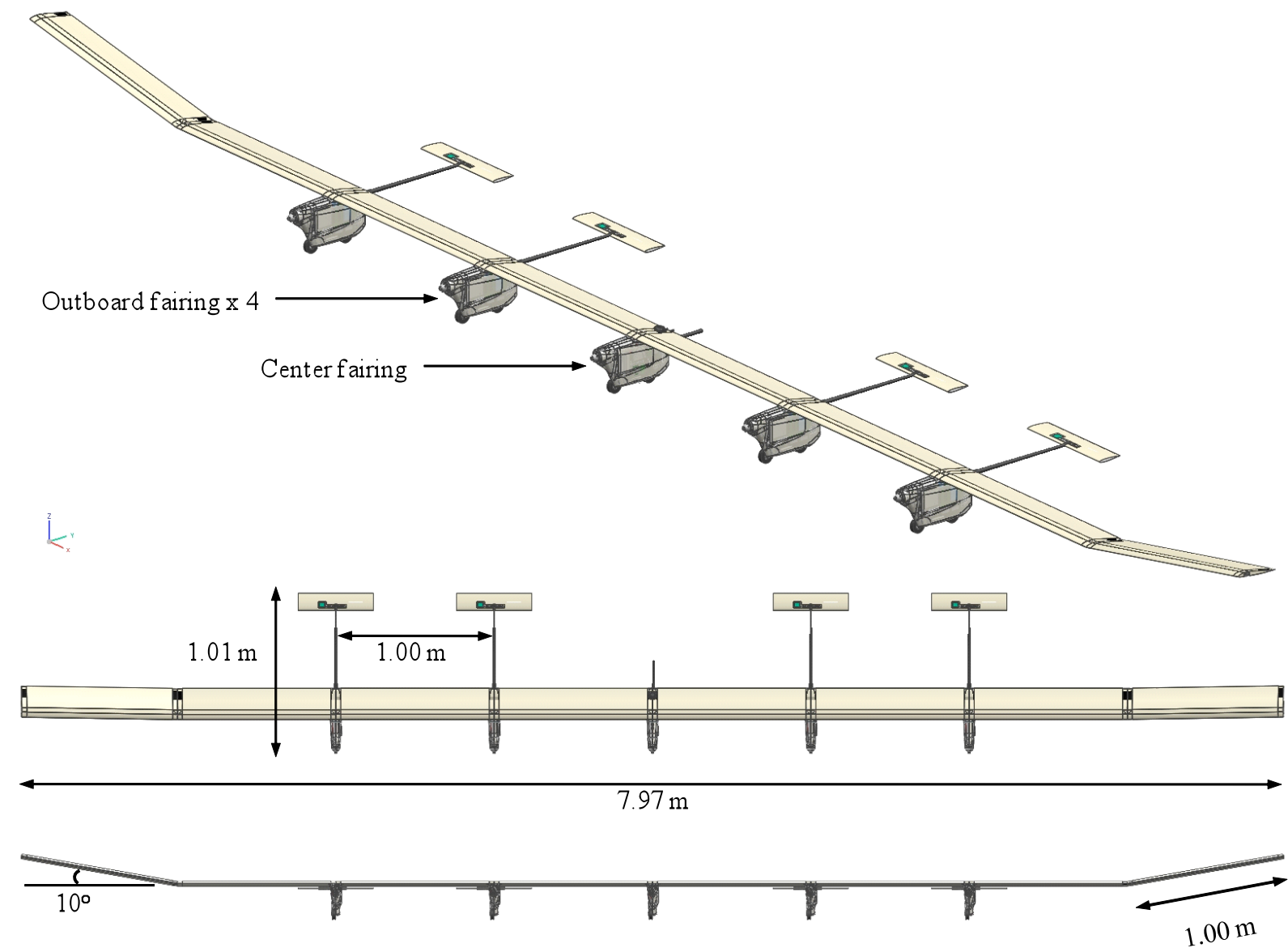

Figure 3. Complete X-HALE CAD assembly: isometric, top, and front views 
Table 1. X-HALE SUAS main characteristics.

\begin{tabular}{lcc}
\hline \hline Wing Span & 8 & $\mathrm{~m}$ \\
Chord & 0.2 & $\mathrm{~m}$ \\
Platform Area & 1.6 & $\mathrm{~m}^{2}$ \\
Aspect Ratio & 40 & -- \\
Length & 0.96 & $\mathrm{~m}$ \\
Propeller Diameter & 0.30 & $\mathrm{~m}$ \\
Max Payload & 7.2 & $\mathrm{~kg}$ \\
Max Gross Takeoff Weight & 11.1 & $\mathrm{~kg}$ \\
Power/Weight & 25.5 & $\mathrm{~W} / \mathrm{kg}$ \\
Airspeed & $10-19$ & $\mathrm{~m} / \mathrm{s}$ \\
Endurance & 45 & $\mathrm{~min}$ \\
\hline \hline
\end{tabular}

Five fairings are suspended at the joint of the six inboard sections. The four outboard fairings are modular, i.e., outfitted with identical hardware and electronics. Each contains a Diamond Systems PC104 stack of an Athena II and DMM I/O expansion card for analog to digital conversion and data acquisition. The four outboard fairings also independently control elevons for pitch authority. The central fairing houses the ground station communication system and a Microbotics MIDG GPS/INS reference system. Additionally, the central fairing controls all RC command conditioning, onboard mixing, and autopilot mode control using a Microbotics Servo Switch/Controller (SSC). Each fairing is powered with two lithium polymer batteries: an $11.1 \mathrm{~V} / 1320 \mathrm{mAh}$ electronics battery, and an $11.1 \mathrm{~V} / 6000 \mathrm{mAh}$ motor battery to power each of the $18 \mathrm{~W}$ electric outrunner motors. The outboard motors are capable of differential control to enable vehicle yaw. This overall layout and the primary components within each fairing type are displayed in Figs. 4 and 5.

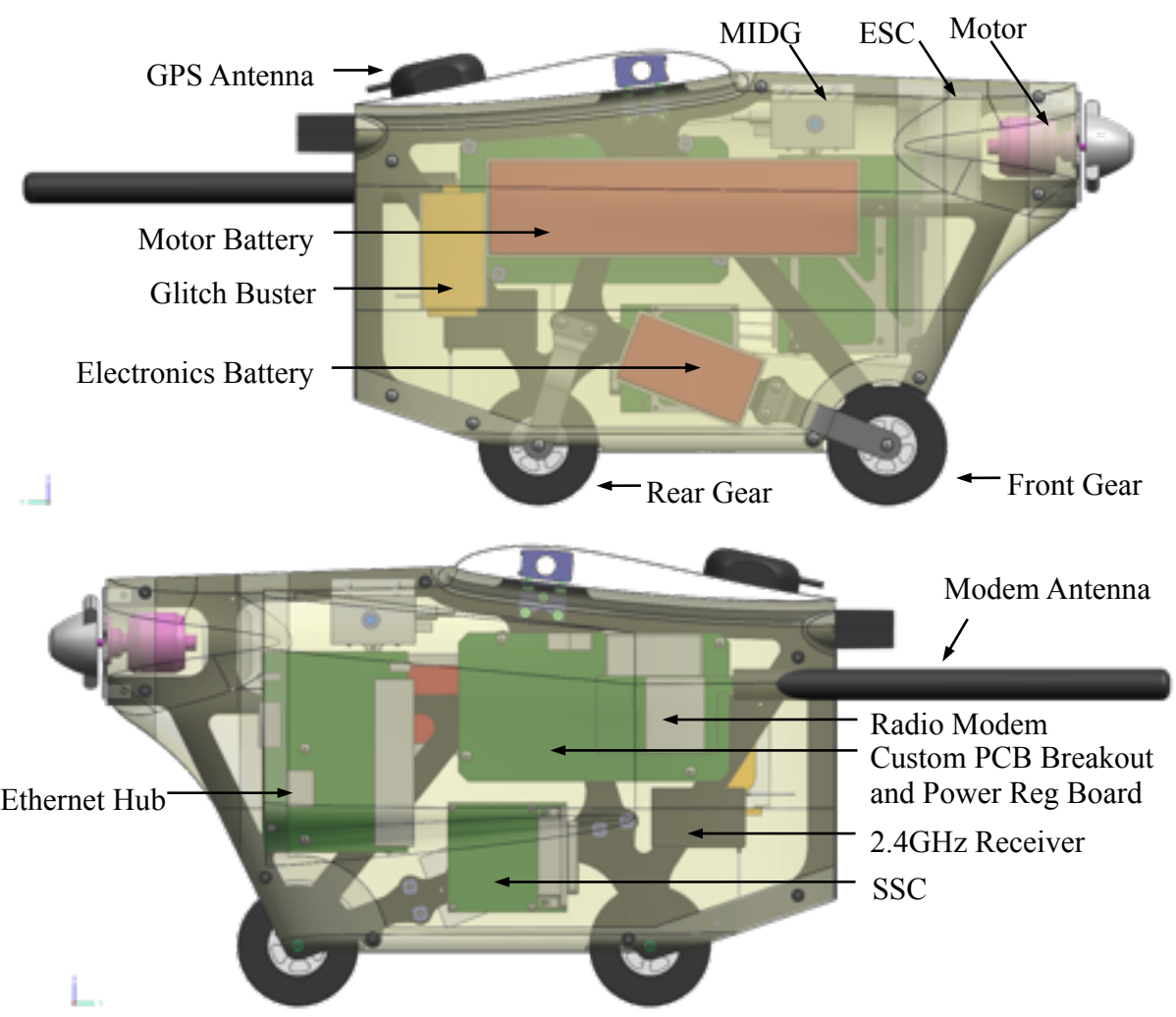

Figure 4. Central fairing assembly 

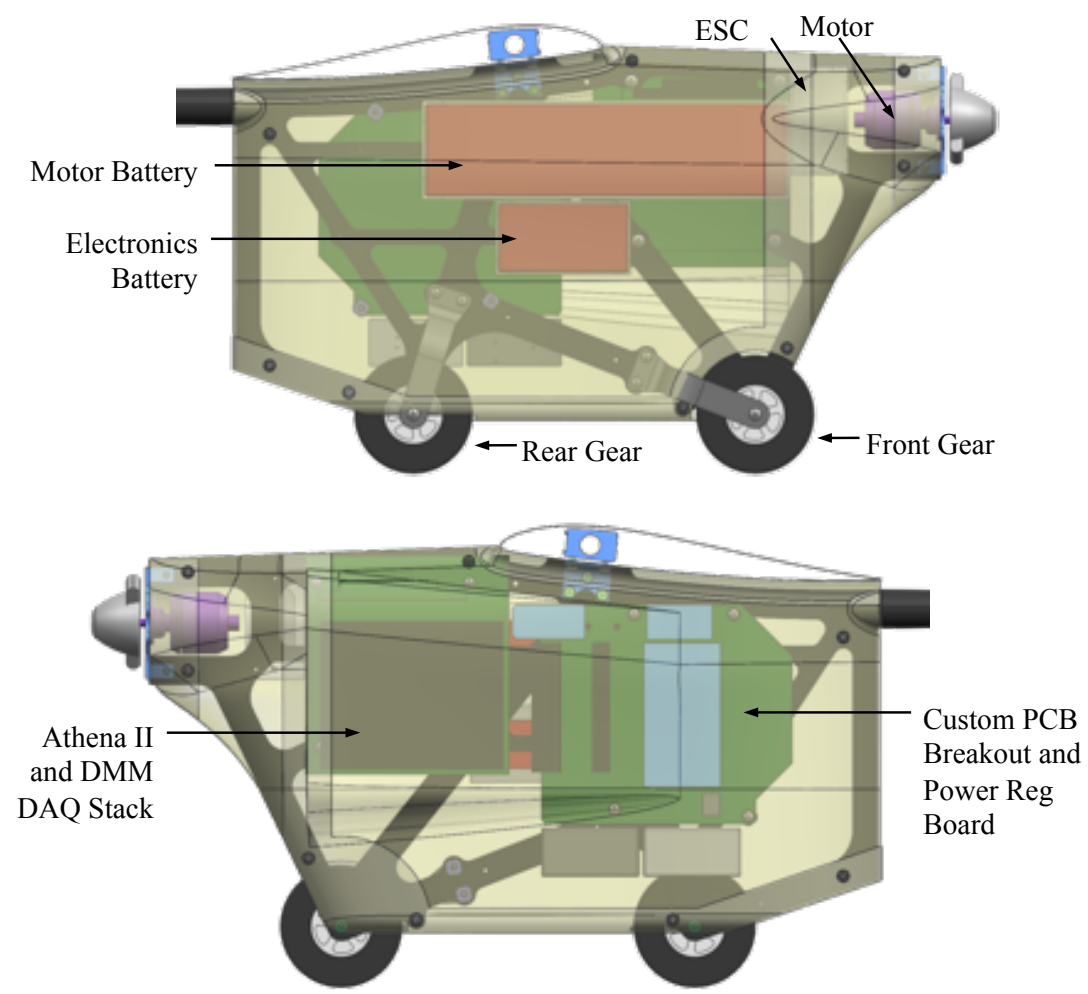

Figure 5. Outboard fairing assembly

Components within each fairing are mounted to a central graphite/epoxy spine. The spine itself is connected to the wing box through custom aluminum L-brackets and joiner located within the wing box of each wing section. This transfers all loads from the fairing through the connection to the wing box only. Finally, the internal components are protected by glass/epoxy skins that are also mounted to the main spine through standoffs and recessed screws. Ram-air intakes designed into the skins profile cool both the motor and primary electronics, such as the Athena II computer and power regulation circuitry, during flight. The rear-flared portion of the skin is also left open to provide an exit vent for the heated air. The skin is identical for each fairing, while the central spine is unique to common outboard fairings. The assembly of the internal fairing structure, skin, and wing joiner is displayed in Fig. 6.

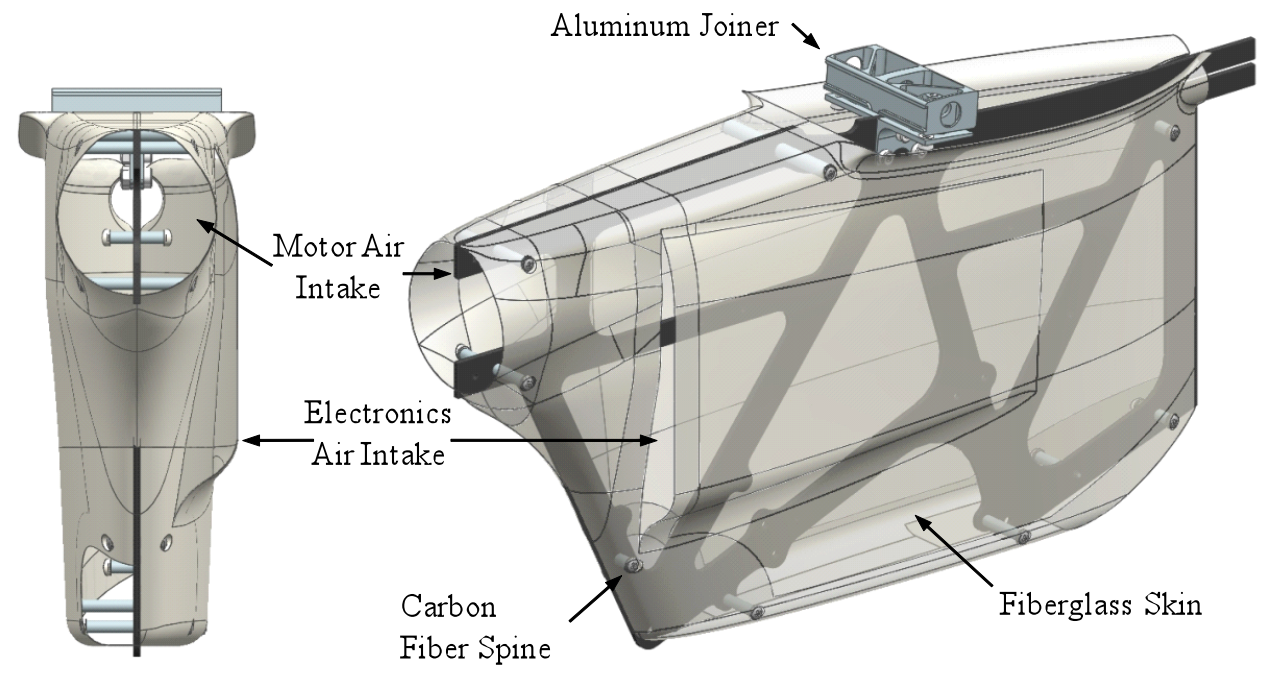

Figure 6. Fairing structure 


\section{B. Airfoil Selection and Characteristics}

Originally, the X-HALE design was inspired by previous HALE aircraft such as Aerovironment's Helios. As a result, the original airframe was a flying wing, which led to reflex type airfoils. Trading $C_{m 0}$, stall angle, and L/D, the final choice was to use the EMX07 reflexed airfoil, displayed with its pressure profile in Fig. 7. Once the design progressed, horizontal tails became an alternative to placing control surfaces within the uniform wing structure. NACA 0012 airfoils were chosen because of the standard behavior of the symmetric airfoil.
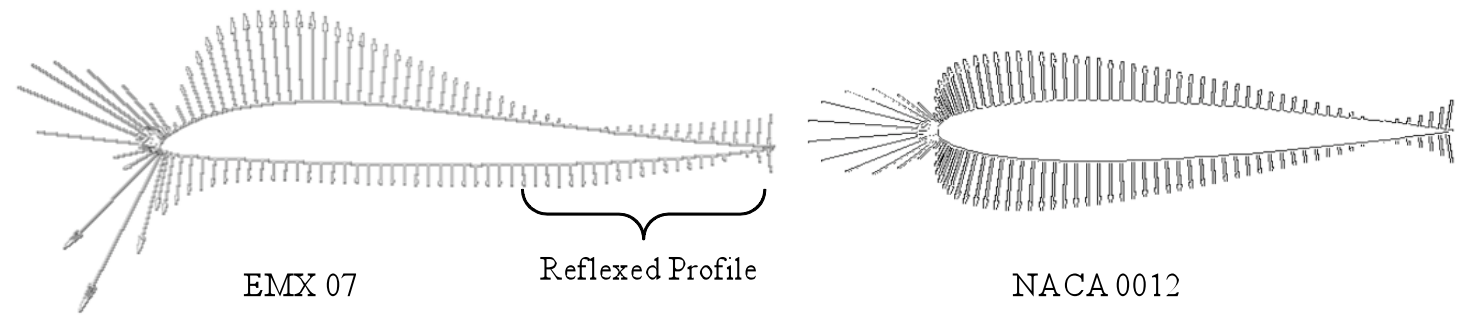

Figure 7. Wing and tail airfoil profiles

With a chord of $0.2 \mathrm{~m}$ and $0.12 \mathrm{~m}$, respectively, the wing and tail Reynolds numbers are low, ranging from 150,000 to 93,000 at a $14 \mathrm{~m} / \mathrm{s}$ reference cruise velocity. This has an effect on the aerodynamic derivatives of each airfoil, but is much more significant for the NACA 0012. Figures 8 and 9 display the basic aerodynamic coefficients for each airfoil at the operating Reynolds number $(150,000)$. Along with those, results for a high Reynolds number of 1,500,000 are included just for comparison. The results displayed in Figs. 8 and 9 show how important it is to provide custom aerodynamic data to a design and/or analysis codes to produce realistic simulation results. Standard aerodynamic derivatives such as $2 \pi$ for $c_{l_{\alpha}}$ are no longer valid especially for the NACA 0012, which ranges from 4.4 to 12 depending on the angle of attack. This dependence on angle of attack is translated into our UM/NAST simulations through look-up tables and calibration functions in order to produce the most realistic simulation results. Table 2 and Table 3 display the resulting aerodynamic derivatives for both airfoils. All these data were calculated using XFOIL. Two-dimensional wind tunnel tests are under way to verify the validity of these properties for the asmanufactured wing and tail sections.

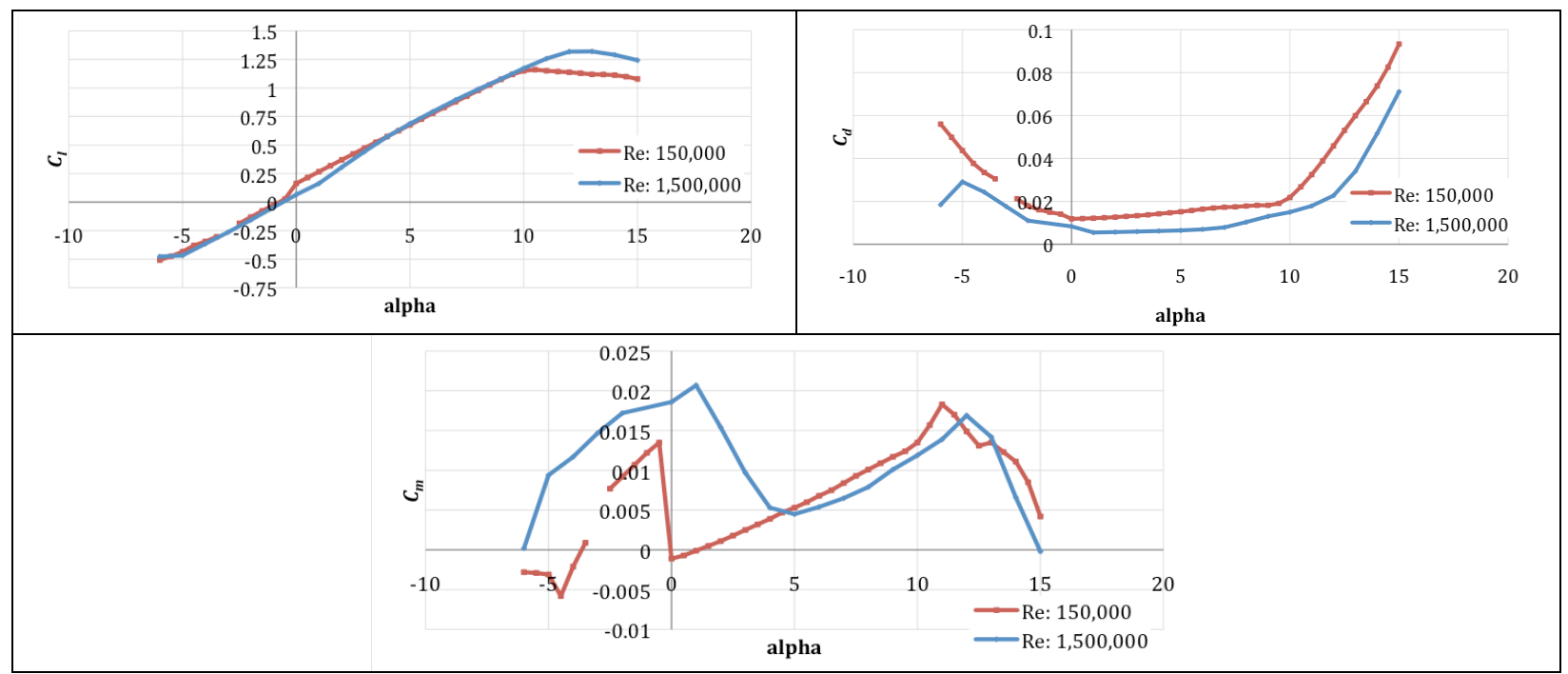

Figure 8. EMX07 airfoil to be used in the main wing (results obtained using XFOIL) 


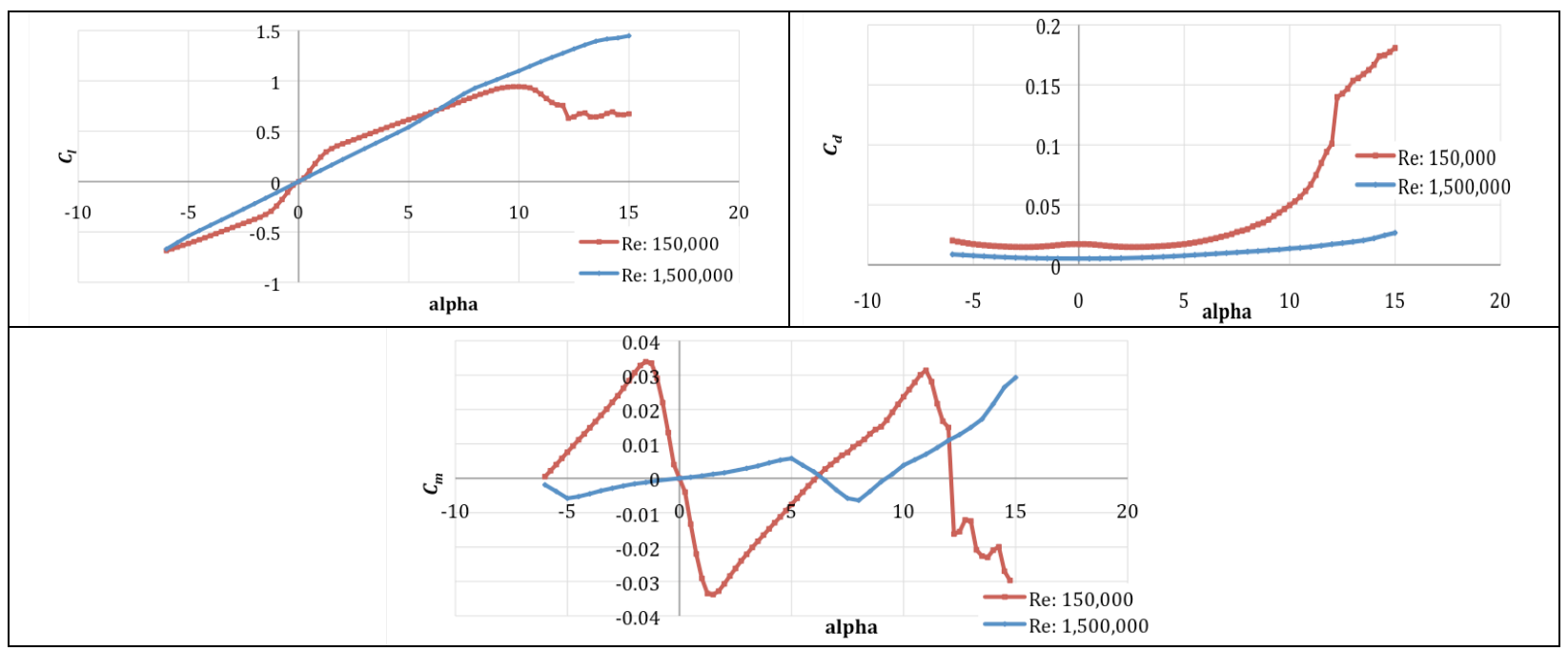

Figure 9. NACA 0012 airfoil to be used in the horizontal tail (results obtained using XFOIL)

Table 2. EMX07 Aerodynamic Derivatives @ $\mathrm{Re}=\mathbf{1 5 0 , 0 0 0}$

\begin{tabular}{|c|c|c|c|}
\hline EMX07 & $\bar{c}$ & $\overline{c_{d}}$ & $c_{m}$ \\
\hline Range $(A O A)$ & & $<-0.5$ & \\
\hline$d c_{x} / d \alpha$ & 5.8034 & -0.4260 & 0.1641 \\
\hline$c_{x 0}$ & 0.0717 & 0.0065 & 0.0150 \\
\hline Range $(A O A)$ & & $(-0.5$ to 10$)$ & \\
\hline$d c_{x} / d \alpha$ & 5.8034 & 0.0402 & 0.0815 \\
\hline$c_{x 0}$ & 0.1630 & 0.0119 & -0.0011 \\
\hline Range $(A O A)$ & & $>10$ & \\
\hline$d c_{x} / d \alpha$ & -0.2521 & 0.7739 & -0.2020 \\
\hline$c_{x 0}$ & 1.1944 & -0.1162 & 0.0572 \\
\hline
\end{tabular}

Table 3. NACA 0012 Aerodynamic Derivatives $@ R e=150,000$

\begin{tabular}{|c|c|c|c|}
\hline NACA 0012 & $\overline{c_{l}}$ & $\overline{c_{d}}$ & $c_{m}$ \\
\hline Range (AOA) & 0 to 1.5 & & 0 to 1.5 \\
\hline$d c_{x} / d \alpha$ & 12.0145 & & -1.2930 \\
\hline$c_{x 0}$ & 0.0000 & & 0.0000 \\
\hline Range $(A O A)$ & 1.5 to 10 & 0 to 10 & 1.5 to 10 \\
\hline$d c_{x} d d \alpha$ & 4.4746 & & 0.4119 \\
\hline$c_{x 0}$ & 0.2240 & 0.0160 & -0.0435 \\
\hline $\mathbf{A}$ & & 32.400 & \\
\hline B & & -1.306 & \\
\hline C & & -0.024 & \\
\hline Range (AOA) & & $>10$ & \\
\hline$d c_{x} d d \alpha$ & 0.0000 & 1.6085 & -0.8318 \\
\hline$c_{x 0}$ & 0.6000 & -0.2359 & 0.1850 \\
\hline
\end{tabular}

8

American Institute of Aeronautics and Astronautics 


\section{Wing Design and Fabrication ${ }^{\dagger}$}

The purpose and challenge for X-HALE is to prototype and study the behavior of high wing flexibility inherent in HALE aircraft through experiment and theory. These inspire multiple design requirements for the wing structure, which include:

- A predictable and controlled cross-sectional properties

- The use of lightweight, flexible, but strong materials

- The ability to be disassembled the vehicle due to transportation and manufacturing constraints

- The structural behavior of a uniform beam despite a modular design As a result both materials and manufacturing processes are selected and prototyped to satisfy these criteria.

Prepreg composites are used as the primary structural material because of their lightweight, controlled, and documented material properties. The main wing structure is composed of a wing box made from Hexcel E-glass 120/F155 prepreg fabric wrapped around a Rohacell 31-IG high temperature foam core. The wing box includes five continuous layers of E-glass in a 0/90 orientation to provide a robust thickness to the structure. To finish the airfoil profile, additional foam is added to leading and trailing edge and wrapped with a final layer of 0/90 e-glass. This layup composes the majority of the wing and can be visualized in Section B-B and Detail D of Fig. 10. However, $3.18 \mathrm{~cm}(3.18 \%)$ from either end of the wing section contains a different layup. This layup includes layers of IM7/977-3 graphite/epoxy unidirectional tape to reinforce and complete the internal geometry of the wing joint, which is shown in Section A-A and Detail C and will be described later. Further details on the layup can be found in Table 4.

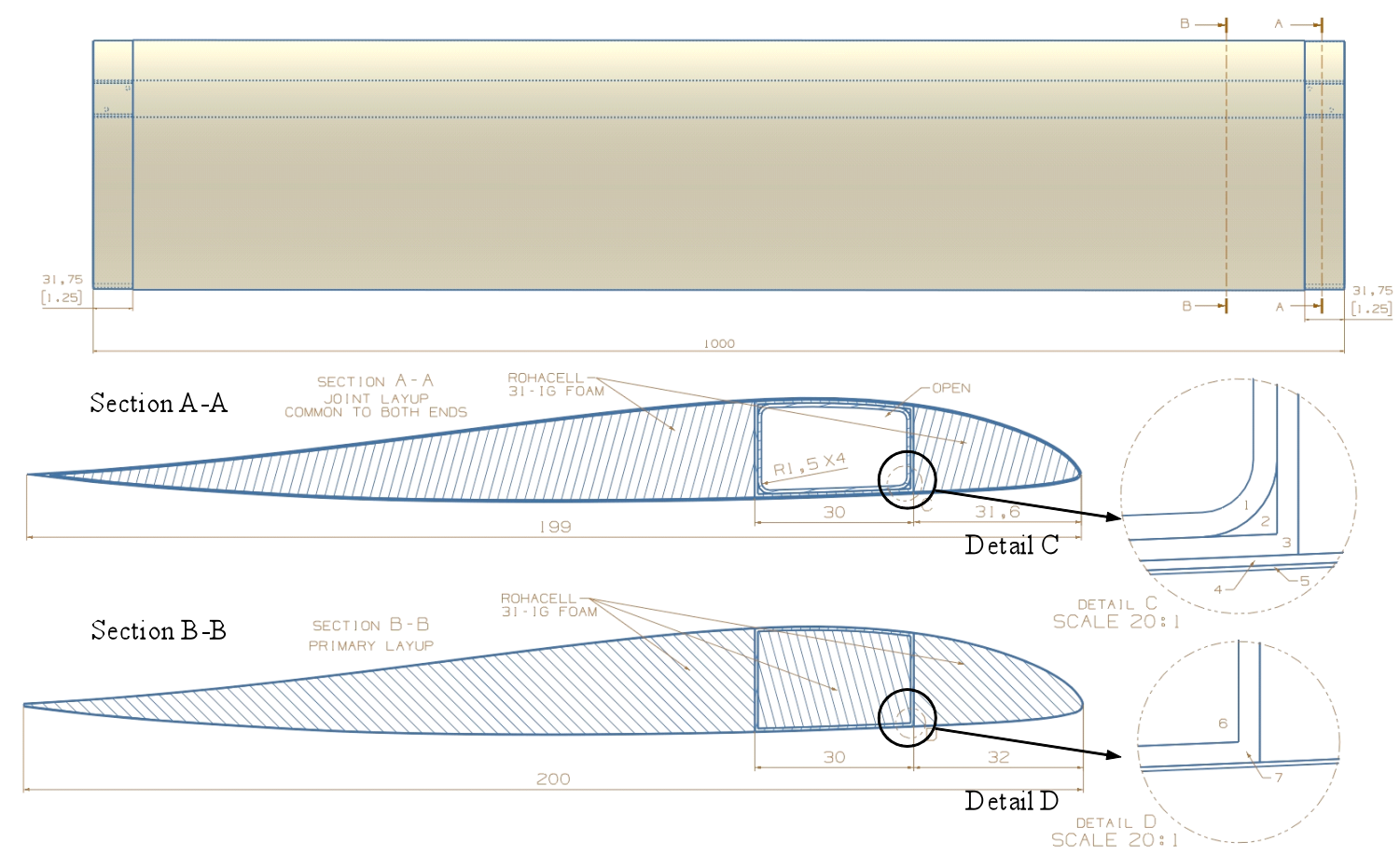

Figure 10. Primary wing layup cross section

Because the layup in section A-A only takes up about 3\% of the total mass wing section span, it is not accounted for in the simulation input that will be detailed later in Section III. The purpose of it in our physical model is to create a robust wing joint layup that can easily withstand inertial and landing loads from the fairings.

Meticulous attention has also been given to the fabrication and flight hardware used at each joint. The joint is designed to transfer bending loads through the wing box and torsional loads through the shear skin. Therefore, it must be made with tight tolerances to ensure a uniform load transfer. With this is mind, the inspiration for the current wing box joint hardware is simplicity as it is composed of a single machined aluminum component (Fig. 11). Within this single piece of hardware we have the ability to join both wing sections, fasten the fairing structure, and

${ }^{\dagger}$ Although on what follows only the wing is described, similar manufacturing procedure is used for the horizontal tails. 
route any internal wing wiring without hindering the ability to remove or replace any single primary component. Furthermore, the joiner is machined to match the profile of the aluminum mold insert used to layup and align the internal wing box geometry.

Table 4. Composite Layup Legend for Detail C and D

\begin{tabular}{lllll}
\hline \hline Label & Plies & Material & Thickness $(\mathbf{m m})$ & Orientation* $^{*}$ \\
\hline 1 & 5 & E-Glass 120/F155 & 0.12 & $90,90,90,90,90$ \\
2 & n/a & IM7/977-3 Dowel & 1. (diameter) & 0 \\
3 & 5 & E-Glass 120/F155 & 0.12 & $0,0,0,0,0$ \\
4 & 2 & IM7/977-3 Tape & 0.137 & 0,0 \\
5 & 1 & E-Glass 120/F155 & 0.12 & 0 \\
6 & 5 & E-Glass 120/F155 & 0.12 & $0,0,0,0,0$ \\
7 & 1 & E-Glass 120/F155 & 0.12 & 0 \\
\hline \hline
\end{tabular}

$* 0$ is along wing span

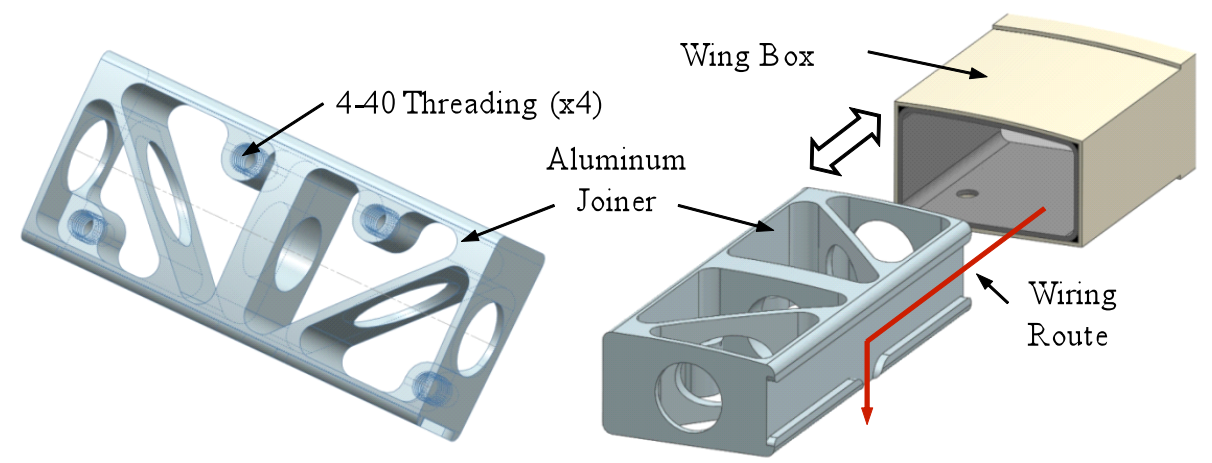

Figure 11. Aluminum joiner and wing box assembly

To help with the transfer of the torsional loads, a fiberglass sleeve is used that slides around the wing joint (Fig. 12). The airfoil profile at the end of each wing section is slightly offset allowing the sleeve to provide a smooth transition for the airfoil surface across the joint. The use of machined components and molds within each joint component is critical in guaranteeing a rigid and straight connection across the wing span satisfying the fourth wing design criterion discussed before.

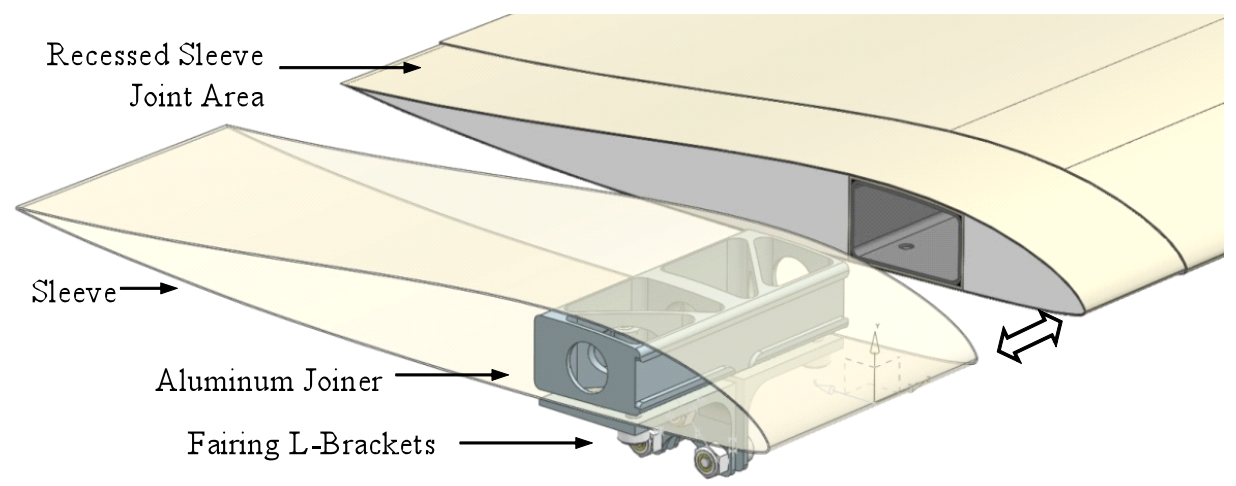

Figure 12. Wing joint composition

Exceptional care has been taken into creating the tools necessary to manufacture identical wing sections. Robust aluminum female molds have been machined in-house on a CNC bed mill and sanded to a mirror finish to both produce the most accurate airfoil profile and smoothest surface finish possible. The use of female molds has another benefit: it allows the foam core to be oversized and compressed by the mold surface when closed, which helps bond strain gages to the internal fiberglass surface and aides in a smooth surface finish.

Two curing cycles are required to create one full wing section. First, the wing box is fabricated. As previously described, layers of E-glass are wrapped around foam sections shaped to the wing box profile and the carbon fiber 
that makes up each wing joint, which has already been wrapped around plugs that attached to alignment jigs. The alignment jigs then slide onto pins embedded in the wing mold. At this point the mold will only apply pressure to the top and bottom surface since the airfoil profile is not complete, so solid epoxy leading and trailing edge forms, referred as hardbacks, are placed in the mold to apply pressure to the front and back of the wing box. Once the wing box has completed a curing cycle, foam leading and trail edge section replace the hardbacks, and the entire assembly is wrapped with a single layer of E-glass and additional layer of graphite/epoxy at the wing joints. The wing is again cured in an autoclave producing one complete wing.

\section{Sensor Layout and Design}

To monitor X-HALE's complex aeroelastic behavior during flight, a sizeable data acquisition network must be used. X-HALE is equipped with four Athena II single board computers. Each has a $500 \mathrm{MHz}$ processor, $256 \mathrm{MB}$ of RAM, and a 1GB flash card to process and store collected analog data. Each Athena II has a 16 single-ended analog to digital conversion (ADC) circuit that is supplemented with 16 additional differential channels from a stacked PC104 DMM32 I/O expansion card. The airframe is equipped to carry four of those pairs (Fig. 13): one in each outboard fairing.
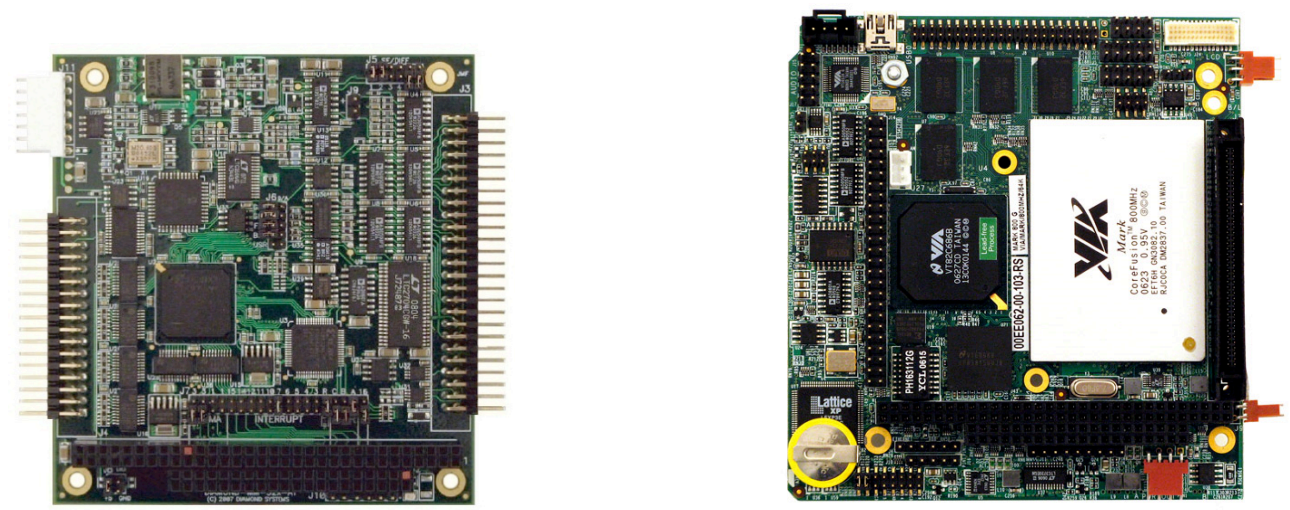

Figure 13. Diamond systems DMM32 I/O PC104 card and Athena II single board computer

Each board is designated to collect data from specific types of sensors at different rates. The sensors onboard XHALE are categorized into two groups: science and housekeeping sensors. Science data includes all strain gages and accelerometers used in sole support to the aeroelastic tests. On the other hand, housekeeping data includes sensors that also monitor the health of the aircraft, such as temperature and battery voltage; flight conditions, such as airspeed, angle of attack, side-slip angle, Euler angles, and GPS location; and control inputs, such as motor RPM and control surface deflections. The DMM card is tasked with sampling only the strain gage data at $1 \mathrm{kHz}$. The Athena DAQ circuit samples the accelerometers and housekeeping sensors at lower rates adjustable by the user. Figure 14 and Table 5 describe the positioning of each sensor and their relative DAQ system.

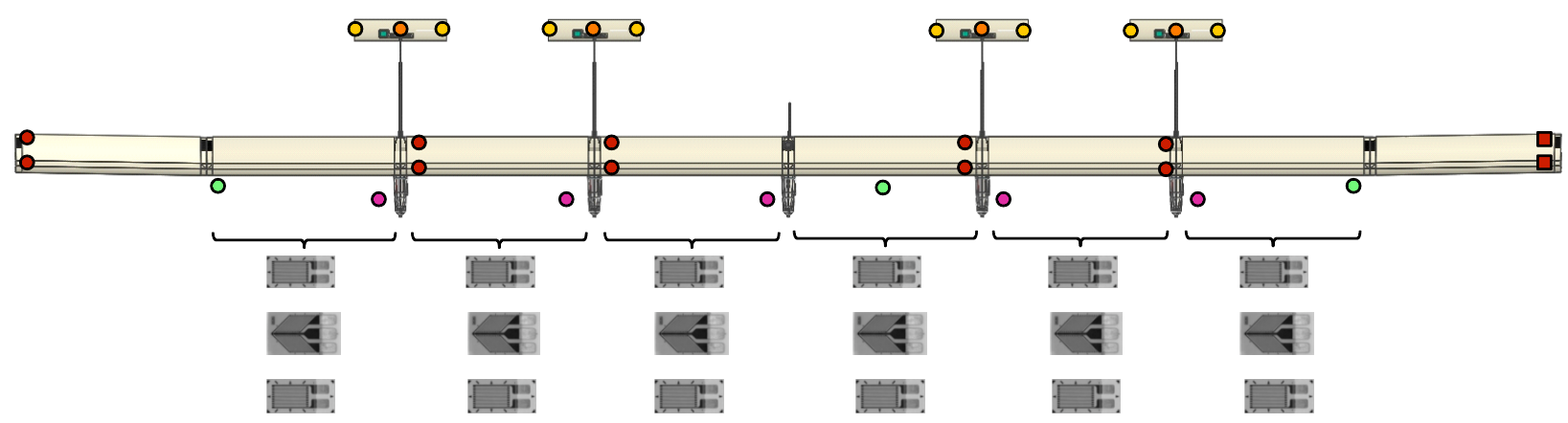

Figure 14. General sensor layout on X-HALE plan-form view 
Table 5. List of Sensor and Their Positioning on the Plan-form

\begin{tabular}{|c|c|c|c|c|}
\hline Board/Sensor & Color & Number & Channels & Type \\
\hline DMM32 I/O PC104 card & & 4 & 64 (Avail) & \multirow{4}{*}{ Differential } \\
\hline Bending Strain Gage Bridge & in: & 26 & 26 & \\
\hline Shear Strain Gage Bridge & & 22 & 22 & \\
\hline In Plane Strain Gage Bridge & H: & 16 & 16 & \\
\hline Athena II board & & 4 & 64 (Avail) & \multirow{9}{*}{ Single Ended } \\
\hline 2 Axis Accelerometer & & 12 & 24 & \\
\hline 1 Axis Accelerometer & & 8 & 8 & \\
\hline 5 Hole Probe & & 3 & 9 & \\
\hline Tail Potentiometer & & 4 & 4 & \\
\hline Fairing Housekeeping & & & & \\
\hline Voltage Divider Circuit & & 10 & 10 & \\
\hline Motor RPM & & 5 & 5 & \\
\hline Thermocouple* & & 4 & 4 & \\
\hline
\end{tabular}

With 128 possible sensors, it is important that the data be time synchronized. To do this and compile the data from all fairings, the stack in fairing 1 is programmed as a master while the others are programmed as slaves. The master triggers data collection trough a digital pulse. Once this occurs each stack independently samples all science and housekeeping sensors. High-speed science data is stored locally on each Athena II while the housekeeping data is sent to the master via an onboard Ethernet network. The master then stores the data and sends it to a radio modem located in the central fairing to a ground station monitored during flight. To ensure a reliable $1 \mathrm{kHz}$ data acquisition rate is possible, the QNX real-time operating system is used and analog data is stored in a high-speed RAM queue capable of supporting over $1 / 2$ hour of continuously acquired data. The ground station operator can specify when to start and stop data acquisition cycles; when active acquisition is inactive data previously stored is then written to permanent storage halting either when writing is complete or when the operator restarts data acquisition.

\section{E. Flight Control System}

During the majority of the flight, X-HALE is completely under RC command, with manual servo commands monitored and stored onboard. It is only during cruise flight testing phases that predetermined motor and control surface commands are issued by the onboard master flight computer. In early testing, open loop (scripted) command sequences designed to appropriately excite aeroelastic behaviors will be the only autopilot control capability. Based on analyses from this testing, we will then migrate to a feedback control strategy appropriate for the very-flexible body.

The X-HALE has nine RC components composed of five motors and four tails. Ailerons are also included on each of the dihedral wing sections. However, they will only be used during testing phases of the flight to force deformations into the wing structure. Mixing both on the ground through the RC transmitter and onboard through the SSC allows the pilot to control each RC component through the standard 4 channel thrust, yaw, pitch, and roll joysticks on the transmitter, or trigger the autopilot phase through an additional channel such as a gear or flap switch. All commands are stored onboard and are also sent to the ground station using the Athena II. To supplement the PWM commands, sensors monitor the physical motion of each control component to alleviate any errors in the conversion to mechanical energy. Figure 15 displays a functional graphical diagram of the mixing phases of the RC signals.

Although specific mixing percentages will be determined on the benchtop and refined between early flight tests, the strategy for control mixing will be as follows. Thrust (throttle joystick) will ramp from 0 to $100 \%$ equally over all motors to balance battery use given zero yaw (rudder joystick) command. With the need to apply a yawing moment, the two outboard motors will be issued a differential thrust that, within saturation limits, applies the appropriate moment while maintaining the desired total thrust. Similarly, the horizontal tail surfaces will be uniformly deflected in response to elevator commands, with the two outboard tails adjusted in opposite directions to obtain any desired roll moment (commanded with the aileron "stick" on the transmitter).

Each outboard fairing has an all movable tail. The Hitec 5125 digital slim wing servo used for actuation and circuitry used to record the position of the tail are embedded within the NACA 0012 airfoil profile along the tail axel. With this arrangement, the axel is fixed to the boom while the tail rotates around it. The physical angular 
position of the tail is measured by the change in resistance from a rotary potentiometer to provide a direct measurement of the PWM signal that is sent to the servo. Figure 16 displays the tail and its internal hardware.

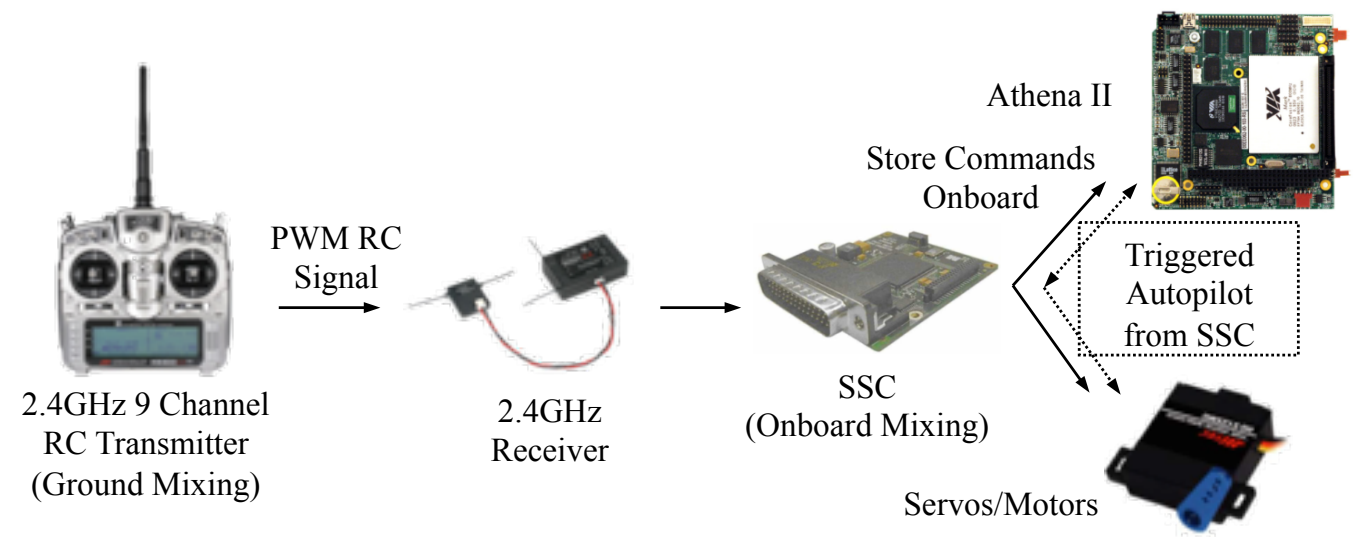

Figure 15. Functional diagram of RC command mixing sequence

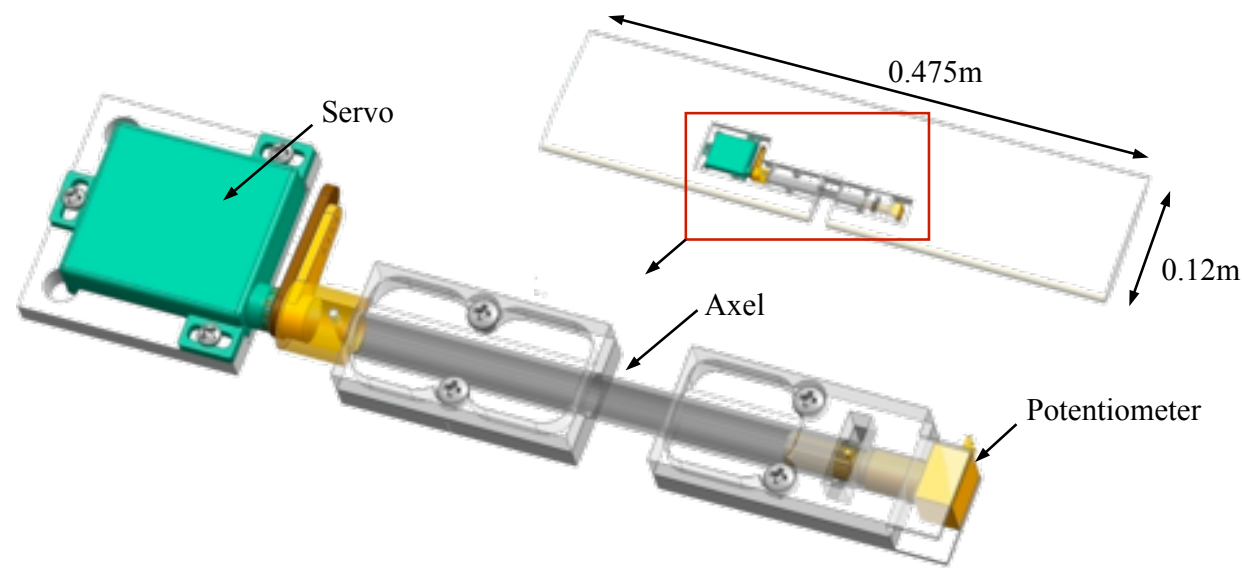

Figure 16. Tail and internal hardware

The X-HALE is propelled by five PJS 1200 outrunner motors, each paired with a 12x6 Graupner CAM folding propeller. Each motor has a maximum static thrust of approximately $10 \mathrm{~N}$ with a maximum power draw of $18 \mathrm{~W}$. Wind tunnel tests using a sting balance were completed to track the 6-DOF dynamic force and moment performance of the power train between $10 \mathrm{~m} / \mathrm{s}$ and $20 \mathrm{~m} / \mathrm{s}$. The test setup and thrust results are displayed in Figs. 17 and 18 .
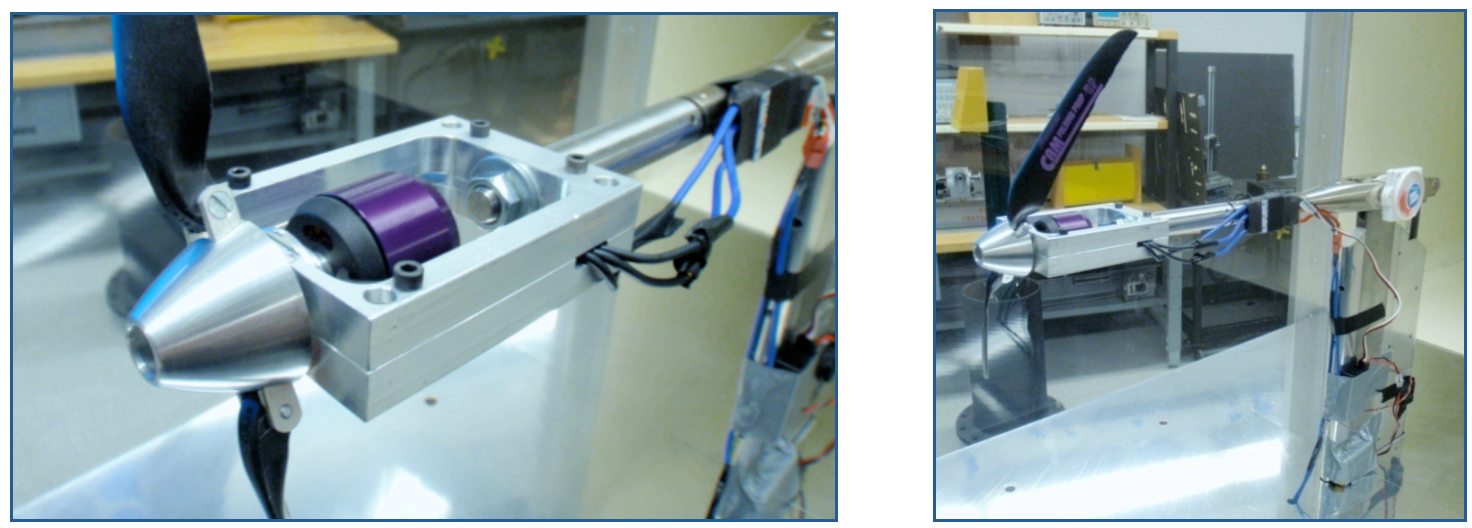

Figure 17. 2'x2' wind tunnel test setup for calibration of the propulsion assembly

American Institute of Aeronautics and Astronautics 


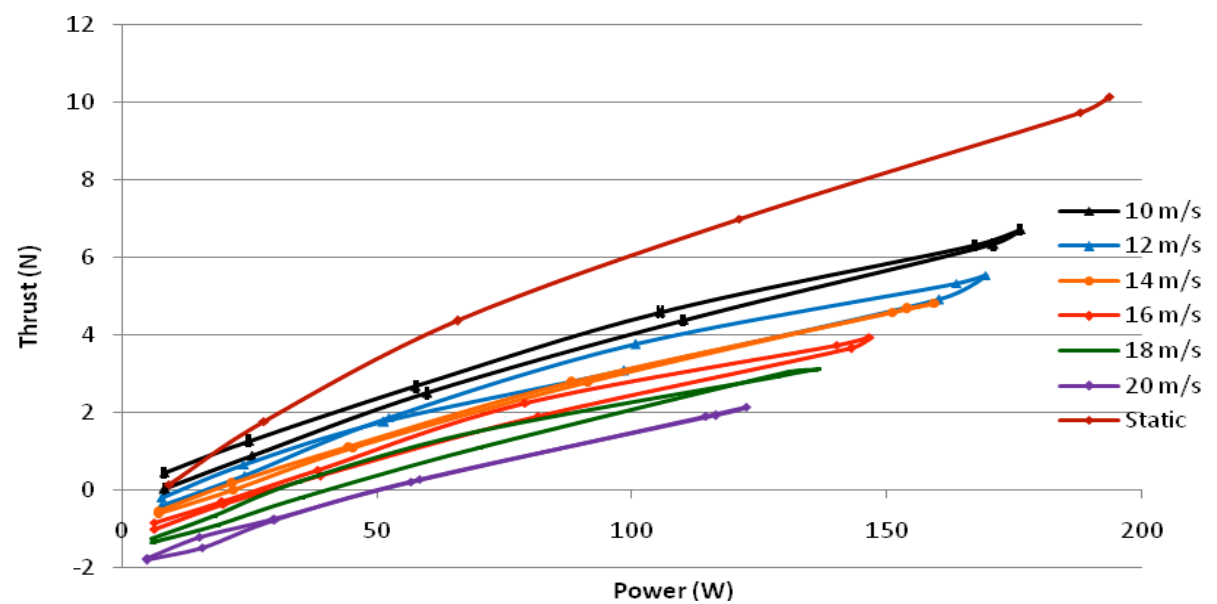

Figure 18. Input power vs. thrust from wind tunnel testing for flight regime velocities

Due to inconsistencies within motor performance characteristics, each motor is tested and calibrated independently. From these tests we can achieve and calibrate an accurate thrust profile across the span of the aircraft.

\section{X-HALE Aeroelastic Simulations}

A model of the X-HALE was created in UM/NAST to support its nonlinear aeroelastic analysis and design. In what follows, numerical aeroelastic and flight dynamic simulations are performed based on the model and some fundamental aeroelastic characteristics of the model are identified. Extreme flight conditions are presented to indicate the limits in which the design can be taken.

\section{A. Platform Data}

Figure 19 illustrates the X-HALE model created in UM/NAST, which features an 8-m span. The outer 1-m long members are built with a dihedral angle of $10^{\circ}$. Five pods are modeled as vertical lifting surfaces with applied follower concentrated forces to simulate the motor thrust. Four tails are modeled as all-movable horizontal surfaces. Member properties are listed in Tables 6 and 7. Note that the booms, tails, and pods are models as rigid members, and no rigidity properties are provided for them. Ailerons are modeled on the outer dihedral members, which occupy $25 \%$ of the chord. The inertias of the spine and covers of the pods are neglected, while concentrated inertias are attached inside the pods, which come from mainly the electronic equipments.

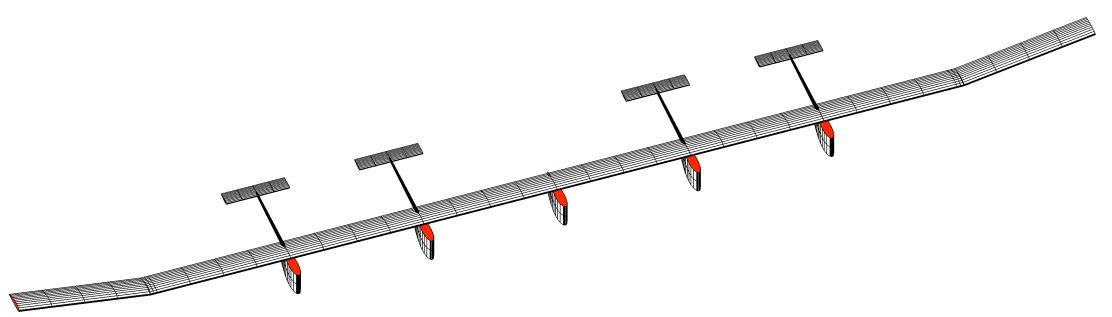

Figure 19. UM/NAST model of the X-HALE aircraft.

\section{B. Trim Results}

The vehicle is trimmed for equal lift and weight, and zero pitching moment about its center of gravity at level flight at 30-m altitude. The flight velocity ranges from 12 to $20 \mathrm{~m} / \mathrm{s}$. The trim results are plotted in Fig. 20. Figure 21 compares the deformed shape at the trimmed condition $(14 \mathrm{~m} / \mathrm{s})$ and the reference shape, where the large static deformation can be found. The vehicle is highly flexible and the tip deflection at this trimmed state is about $37 \%$ of the half span. 
Table 6. Member properties of the X-HALE model

\begin{tabular}{|c|c|c|c|c|c|}
\hline & Wing & Booms & Tails & Pods & Units \\
\hline Ref. axis location (from L.E.) & 28.78 & 50 & 32.35 & 60.93 & $\%$ chord \\
\hline Center of gravity (from L.E.) & 25 & 50 & 25 & 25 & $\%$ chord \\
\hline Incidence angle & 5 & $\mathrm{~N} / \mathrm{A}$ & 0 & 0 & $\operatorname{deg}$ \\
\hline Chord length $(c)$ / Diameter $(d)$ & 0.20 & $\begin{array}{l}0.024(\mathrm{f}) \\
0.013(\mathrm{r})\end{array}$ & 0.11 & 0.37 & $\mathrm{~m}$ \\
\hline Mass per unit span $(m)$ & 0.319 & 0.01 & 0.129 & -- & $\mathrm{kg} / \mathrm{m}$ \\
\hline Rotational inertia $\left(I_{\mathrm{xx}}\right)$ & $8.09 \times 10^{-4}$ & $2.91 \times 10^{-9}$ & $1.60 \times 10^{-4}$ & -- & $\mathrm{kg} \cdot \mathrm{m}$ \\
\hline Rot./flat bend inertia $\left(I_{\mathrm{xy}}\right)$ & 0 & 0 & 0 & -- & $\mathrm{kg} \cdot \mathrm{m}$ \\
\hline Rot./ in-plane bend inertia $\left(I_{\mathrm{xz}}\right)$ & 0 & 0 & 0 & -- & $\mathrm{kg} \cdot \mathrm{m}$ \\
\hline Flat bend inertia $\left(I_{\mathrm{yy}}\right)$ & $1.22 \times 10^{-5}$ & $1.46 \times 10^{-9}$ & $2.91 \times 10^{-6}$ & -- & $\mathrm{kg} \cdot \mathrm{m}$ \\
\hline Flat/in-plane bend inertia $\left(I_{\mathrm{yz}}\right)$ & $-6.49 \times 10^{-6}$ & 0 & 0 & -- & $\mathrm{kg} \cdot \mathrm{m}$ \\
\hline In-plane bend inertia $\left(I_{\mathrm{zz}}\right)$ & $7.97 \times 10^{-4}$ & $1.46 \times 10^{-9}$ & $1.57 \times 10^{-4}$ & -- & $\mathrm{kg} \cdot \mathrm{m}$ \\
\hline Ext. stiffness $\left(k_{11}\right)$ & $2.14 \times 10^{6}$ & -- & -- & -- & $\mathrm{N}$ \\
\hline Ext./torsion stiffness $\left(k_{12}\right)$ & 0 & -- & -- & -- & $\mathrm{N}$ \\
\hline Ext./ flat bend stiffness $\left(k_{13}\right)$ & $1.54 \times 10^{3}$ & -- & -- & -- & $\mathrm{N}$ \\
\hline Ext./in-plane bend stiffness $\left(k_{14}\right)$ & $-4.91 \times 10^{4}$ & -- & -- & -- & $\mathrm{N}$ \\
\hline Torsion stiffness $\left(k_{22}\right)$ & 72.25 & -- & -- & -- & $\mathrm{N} \cdot \mathrm{m}^{2}$ \\
\hline Tor./flat bend stiffness $\left(k_{23}\right)$ & 0 & -- & -- & -- & $\mathrm{N} \cdot \mathrm{m}^{2}$ \\
\hline Tor./in-plane bend stiffness $\left(k_{24}\right)$ & 0 & -- & -- & -- & $\mathrm{N} \cdot \mathrm{m}^{2}$ \\
\hline Flat bend stiffness $\left(k_{33}\right)$ & 119.57 & -- & -- & -- & $\mathrm{N} \cdot \mathrm{m}^{2}$ \\
\hline Flat/in-plane bend stiffness $\left(k_{34}\right)$ & -46.34 & -- & -- & -- & $\mathrm{N} \cdot \mathrm{m}^{2}$ \\
\hline In-plane bend stiffness $\left(k_{44}\right)$ & $6.35 \times 10^{3}$ & -- & -- & -- & $\mathrm{N} \cdot \mathrm{m}^{2}$ \\
\hline
\end{tabular}

Table 7. List of the concentrated inertias of the X-HALE model

\begin{tabular}{|c|c|c|c|c|c|c|c|c|c|}
\hline & \multicolumn{3}{|c|}{ Outboard pods } & \multicolumn{3}{|c|}{ Center pod } & \multirow{2}{*}{$\begin{array}{c}\text { Inner half } \\
\text { tail }\end{array}$} & \multirow{2}{*}{$\begin{array}{c}\text { Outer half } \\
\text { tail }\end{array}$} & \multirow[b]{2}{*}{ Units } \\
\hline & $\begin{array}{c}\text { Battery } \\
\text { forward cg }\end{array}$ & $\begin{array}{c}\text { Battery } \\
\text { aft cg }\end{array}$ & $\begin{array}{c}\text { Remaining } \\
\text { assembly }\end{array}$ & $\begin{array}{c}\text { Battery } \\
\text { forward cg }\end{array}$ & $\begin{array}{c}\text { Battery } \\
\text { aft cg }\end{array}$ & $\begin{array}{c}\text { Remaining } \\
\text { assembly }\end{array}$ & & & \\
\hline mass & 0.396 & 0.396 & 1.057 & 0.396 & 0.396 & 1.025 & 0.049 & 0.020 & $\mathrm{~kg}$ \\
\hline$x_{c g}^{+}$ & 0.013 & 0.013 & -0.006 & 0.013 & 0.013 & -0.003 & 0.073 & 0.029 & $\mathrm{~m}$ \\
\hline$y_{c g}$ & 0.059 & -0.001 & 0.066 & 0.059 & -0.001 & 0.043 & -0.008 & 0 & $\mathrm{~m}$ \\
\hline$z_{c g}$ & -0.069 & -0.069 & -0.085 & -0.069 & -0.069 & -0.080 & -0.001 & 0 & $\mathrm{~m}$ \\
\hline$I_{x x}$ & \multicolumn{2}{|c|}{$1.160 \times 10^{-3}$} & $1.134 \times 10^{-2}$ & \multicolumn{2}{|c|}{$1.160 \times 10^{-3}$} & $1.476 \times 10^{-2}$ & $4.631 \times 10^{-6}$ & $1.866 \times 10^{-7}$ & $\mathrm{~kg} \cdot \mathrm{m}^{2}$ \\
\hline$I_{y y}$ & \multicolumn{2}{|c|}{$9.485 \times 10^{-5}$} & $3.209 \times 10^{-3}$ & \multicolumn{2}{|c|}{$9.485 \times 10^{-5}$} & $2.816 \times 10^{-3}$ & $2.282 \times 10^{-5}$ & $1.341 \times 10^{-6}$ & $\mathrm{~kg} \cdot \mathrm{m}^{2}$ \\
\hline$I_{z z}$ & \multicolumn{2}{|c|}{$1.098 \times 10^{-3}$} & $8.484 \times 10^{-3}$ & \multicolumn{2}{|c|}{$1.098 \times 10^{-3}$} & $2.503 \times 10^{-4}$ & $2.651 \times 10^{-5}$ & $1.311 \times 10^{-6}$ & $\mathrm{~kg} \cdot \mathrm{m}^{2}$ \\
\hline$I_{x y}$ & \multicolumn{2}{|c|}{0} & $-1.212 \times 10^{-3}$ & \multicolumn{2}{|c|}{0} & $2.322 \times 10^{-4}$ & $-3.190 \times 10^{-6}$ & $1.000 \times 10^{-10}$ & $\mathrm{~kg} \cdot \mathrm{m}^{2}$ \\
\hline$I_{x z}$ & \multicolumn{2}{|c|}{0} & $1.055 \times 10^{-5}$ & \multicolumn{2}{|c|}{0} & $2.267 \times 10^{-5}$ & $-3.057 \times 10^{-7}$ & 0 & $\mathrm{~kg} \cdot \mathrm{m}^{2}$ \\
\hline$I_{y z}$ & \multicolumn{2}{|c|}{0} & $4.595 \times 10^{-5}$ & \multicolumn{2}{|c|}{0} & $4.500 \times 10^{-4}$ & $2.644 \times 10^{-8}$ & 0 & $\mathrm{~kg} \cdot \mathrm{m}^{2}$ \\
\hline
\end{tabular}

\section{Flight under Gust Perturbations}

Gust response of the vehicle is studied in this section. Figure 22 shows the 1-cosine gust profile for the simulation. The gust is symmetrically applied to the vehicle on its flight path. The maximum gust speed is $4 \mathrm{~m} / \mathrm{s}$, while the nominal flight speed is $14 \mathrm{~m} / \mathrm{s}$ at $30 \mathrm{~m}$ altitude.

The aeroelastic and flight dynamic responses of the model with gust perturbation are plotted in Figs. 23 to 27 , compared to a flight condition without gust. Overall, the plunging (Fig. 23) and pitching (Fig. 24) oscillations are excited by the gust perturbation. However, the longitudinal motions are stable, as the amplitudes of the oscillations are reduced in the subsequent cycles. Figure 25 shows the velocity of the body reference frame resolved in the inertia frame. Comparing Figs. 23 and 25, one can identify the phugoid motion, which features the exchange between kinematic (longitudinal velocity) and potential energies.

\footnotetext{
The c.g. locations are measured from the root of each member, i.e., the top surfaces for the pod members and the connection point with the boom for the tail members.
} 

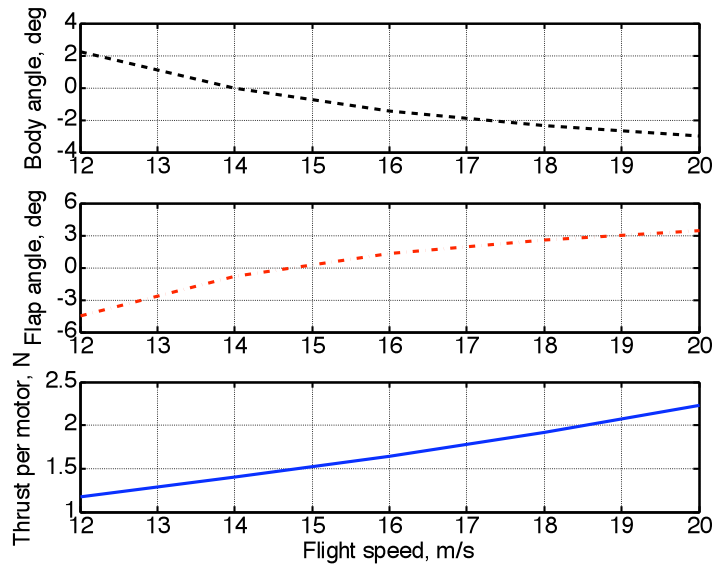

Figure 20. Trim results of the X-HALE model.

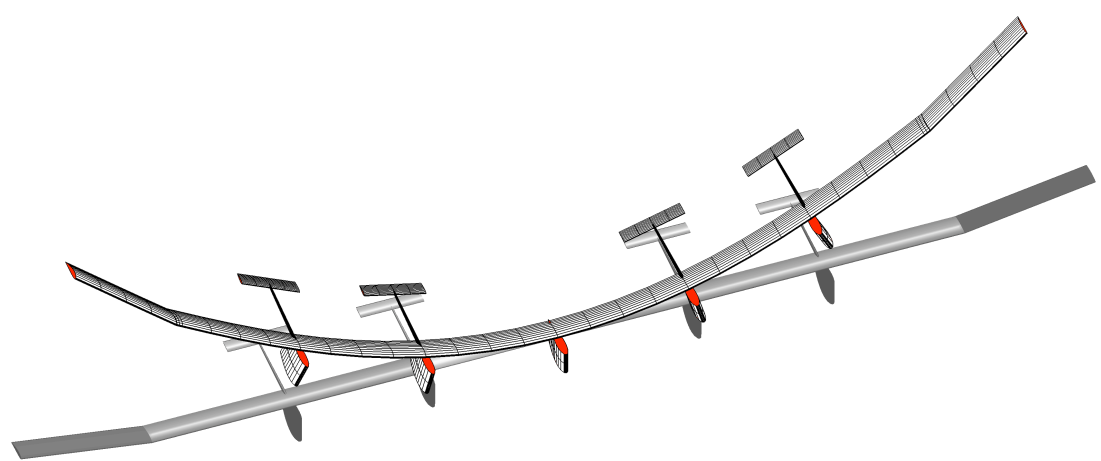

Figure 21. Deformed shape at trim condition (speed: $14 \mathrm{~m} / \mathrm{s}$, with vehicle in grey as the undeformed reference shape).

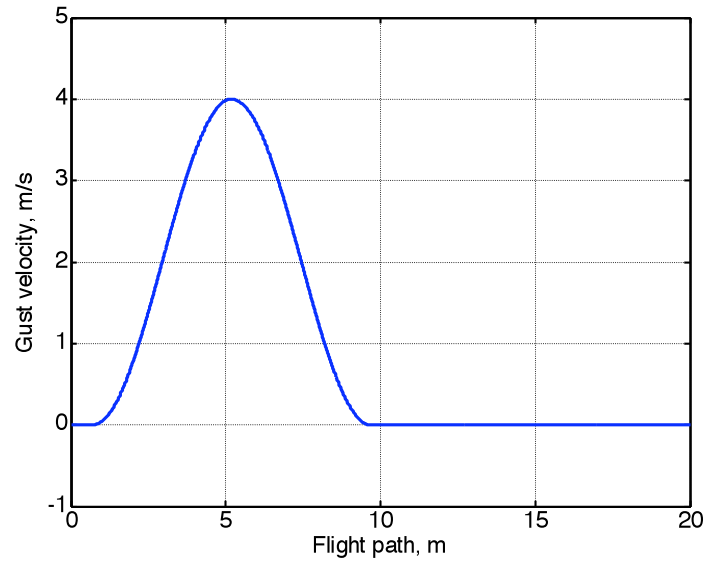

Figure 22. Spatial-distributed gust profile.

Of particular interest is the flexibility of the vehicle. Figure 27 shows the wing tip deflection with the gust perturbation, normalized by the half span of the vehicle. Large wing deformations can be found to be over $43 \%$ of the half span during the vehicle's passing the gust region, after which the oscillation in wing bending is reduced. With such large transient deformation, one needs to check the composite layup strains to verify the structural integrity. The maximum and minimum strain components in each composite fiber direction are given in Table 8 . The normal strain in the longitudinal direction $\left(\varepsilon_{11}\right)$ is over $3000 \mu \varepsilon$. Figure 28 plots the normal strains in the fiber's longitudinal direction, with the minima plotted as positive values. As the local strain components have already gone 
beyond $3000 \mu \varepsilon$ (for a working limit of $4000 \mu \varepsilon$ ), this gust profile can be considered as a critical gust input of what the vehicle can sustain.

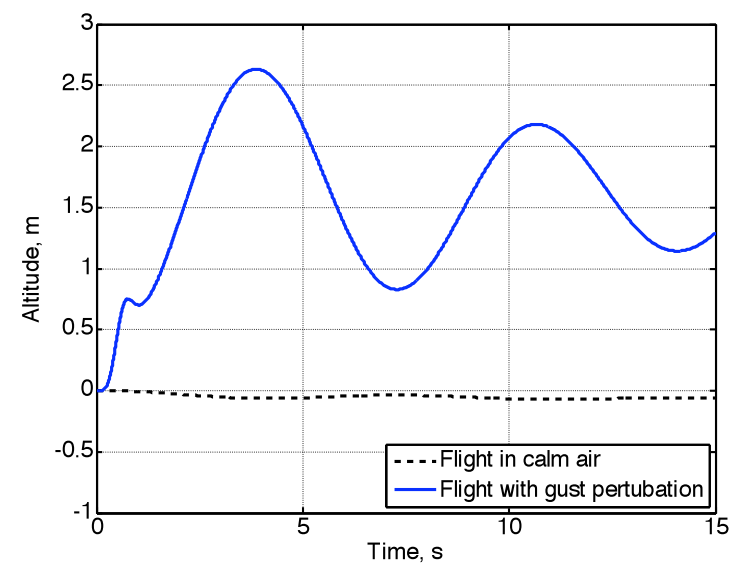

Figure 23. Change of altitude with the gust perturbation.

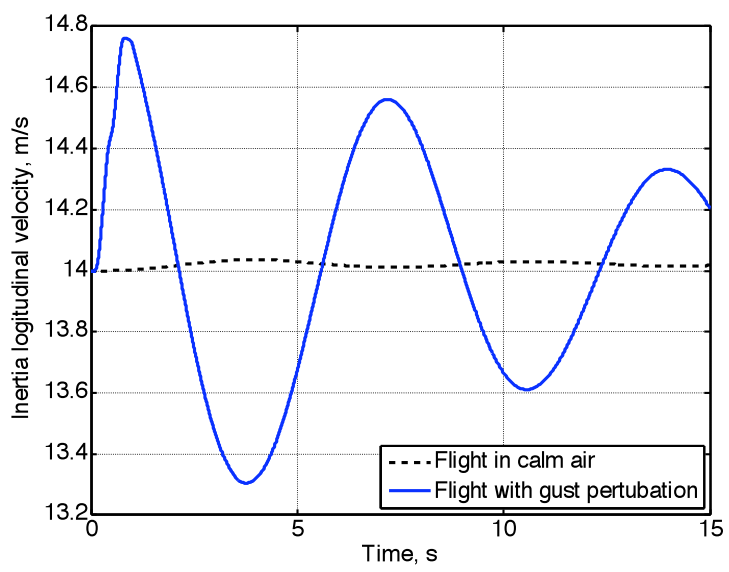

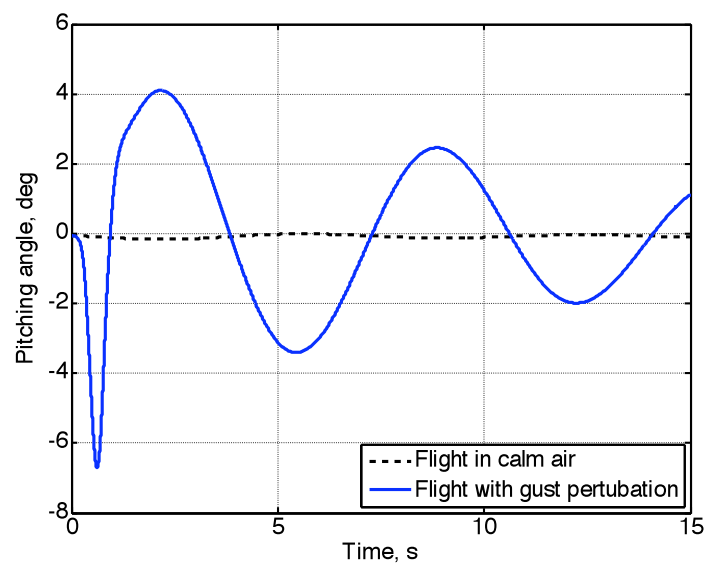

Figure 24. Change of pitching angle with the gust perturbation.

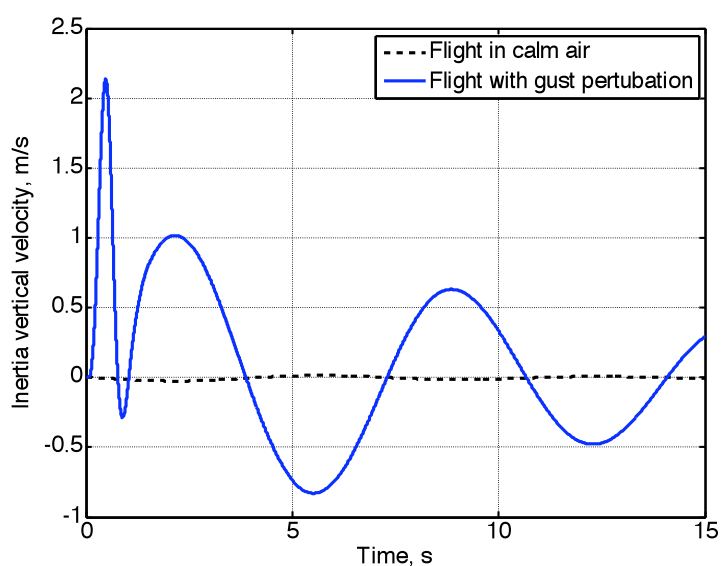

Figure 25. Velocity components in the inertia frame.

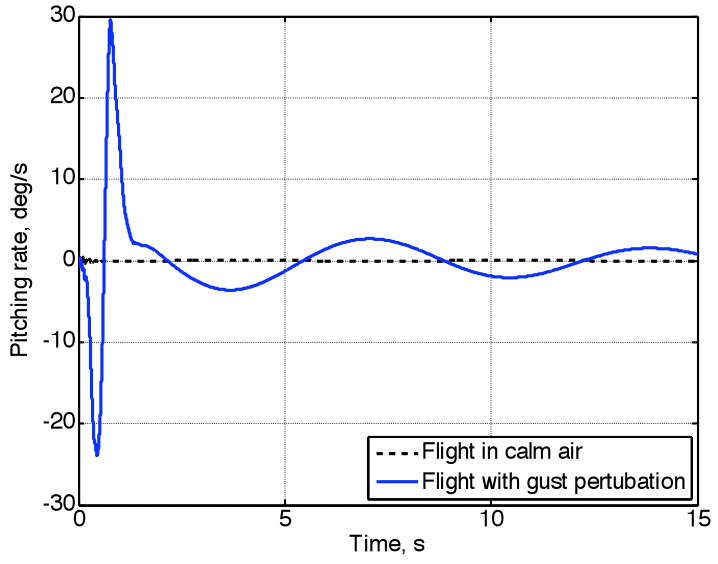

Figure 26. Pitching rate.

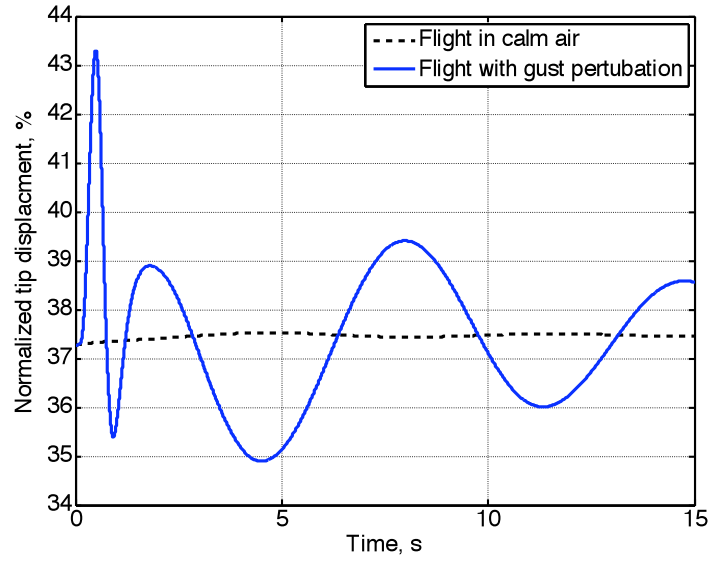

Figure 27. Normalized tip displacement. 
Table 8. List of maximum and minimum strains with the gust perturbation

\begin{tabular}{lcc}
\hline \hline & Maximum $(\mu \varepsilon)$ & Minimum $(\mu \varepsilon)$ \\
\hline$\varepsilon_{11}$ & 3093.4 & -3656.0 \\
$\varepsilon_{12}$ & 895.8 & -886.8 \\
$\varepsilon_{13}$ & 1079.8 & -1068.9 \\
$\varepsilon_{22}$ & 1241.3 & -1099.8 \\
$\varepsilon_{23}$ & 773.0 & -778.1 \\
$\varepsilon_{33}$ & 769.2 & -569.9 \\
\hline \hline
\end{tabular}
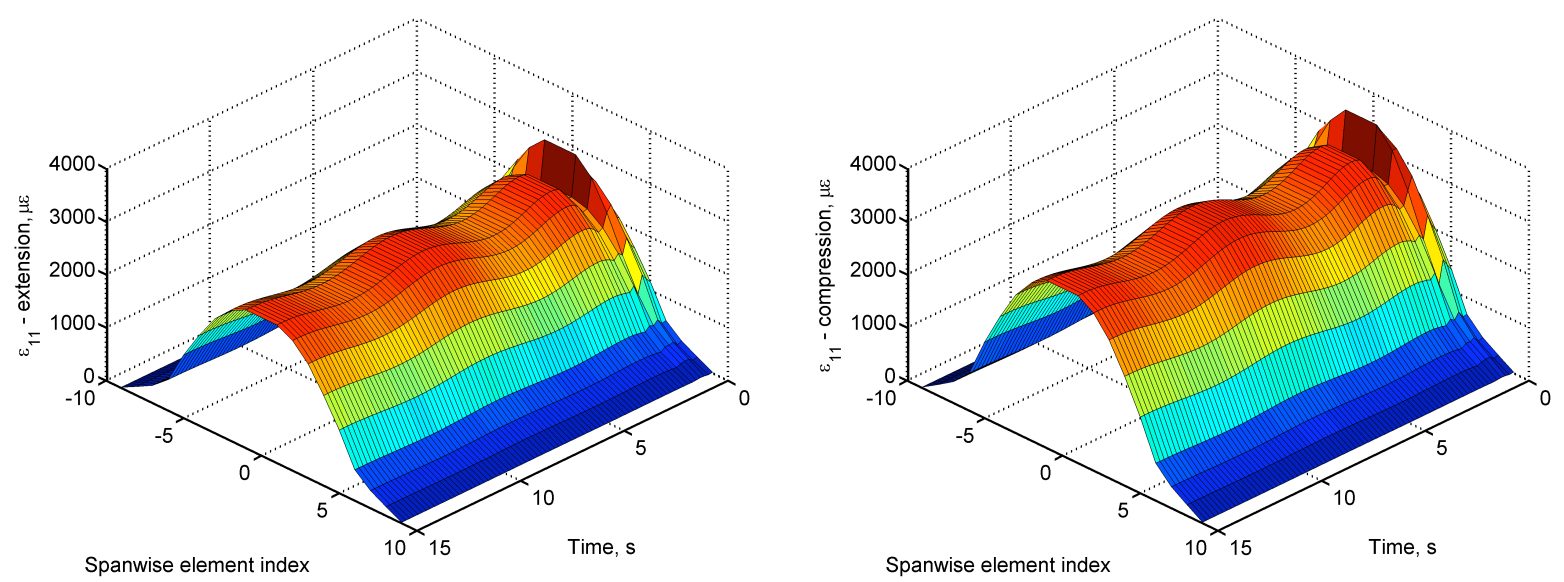

Figure 28. Normal strains in fiber longitudinal direction ( $\varepsilon_{11}$, left: extension; right, compression).

\section{Roll Simulations}

As indicated in the previous section, the vehicle is very flexible. Therefore, its maneuverability needs to be assed to better understand the control surface effectiveness. In this study, the anti-symmetric inputs for the flaps on the dihedral wing members are used to for roll simulations. Figure 29 exemplifies the aileron deflection angle on the left wing. The ailerons start to deflect after 5 seconds (into the simulation) and complete one sinusoidal cycle within 2 seconds. As indicated in Fig. 29, two simulations are performed to study the roll characteristic of the X-HALE model. One has the maximum aileron deflection of $2^{\circ}$, while the other one has the maximum aileron deflection of $5^{\circ}$.

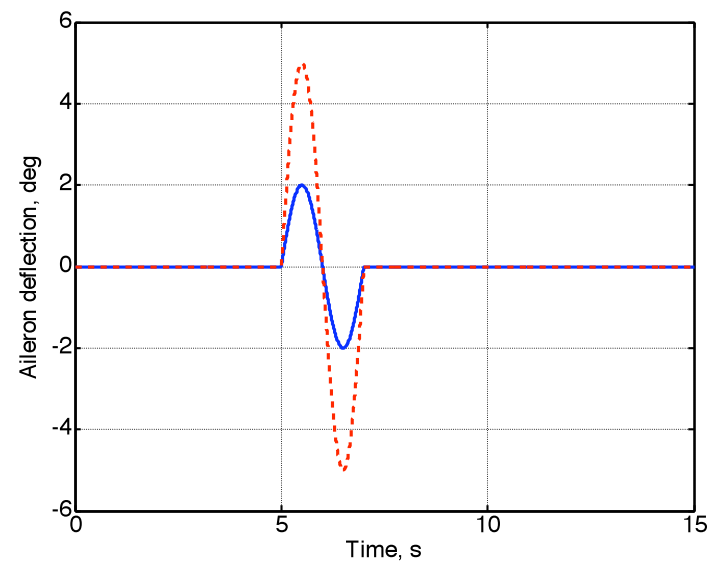

Figure 29. Aileron deflection on the left wing.

First, roll angles and roll rates are compared for the two simulations in Figs. 30 and 31. According to the aileron input, the vehicle is commanded to roll in its positive direction (i.e., right wing down). From the numerical simulation, one my find the vehicle slightly rolls negatively right after the aileron input, which is easier to see in the 
plot of roll rate (Fig. 31). Right after that, the vehicle rolls back to its positive direction. This positive roll does not hold for a long time before the vehicle starts to develop another negative roll due to the evolution of the commanded aileron deflections. After the one-cycle actuation, the oscillation in roll is developed. From Fig. 30, it can also be seen that the roll motion with $5^{\circ}$ actuation is not stable, since the magnitude of roll angle is increased, while the roll after $2^{\circ}$ actuation is still stable.

To verify if the instability in roll after the $5^{\circ}$ actuation is purely rigid-body instability or it is due to the coupling between the flexible and rigid-body degrees of freedom, one more simulation is carried out where the wing flexibility is neglected. The vehicle is first brought to its nonlinear trimmed state and the wing deformation is locked. Only rigid-body degrees of freedom are considered in this simulation. Figures 32 and 33 compare the results from this simulation with the ones from fully nonlinear simulation above. The rigid-body simulation predicts a stable roll motion. Therefore, the instability observed from the fully nonlinear simulation is due to the coupled wing bending and the roll motion of the vehicle.

The actuations of the aileron deflections cause redistribution of the aerodynamic loads on the wings, from which the roll moment is generated. As a consequence, significant yaw moment to the vehicle is also introduced by the aileron deflections and oscillations in yaw can be observed from Fig. 34. Moreover, some pitching vibration is slighting excited (Fig. 35), which could be unstable when the maximum aileron deflection angle is $5^{\circ}$. At the same time, the redistribution of the aerodynamic loads also results in oscillations of the vehicle's body reference frame in the lateral and vertical directions, as shown in Figs. 36 and 37.

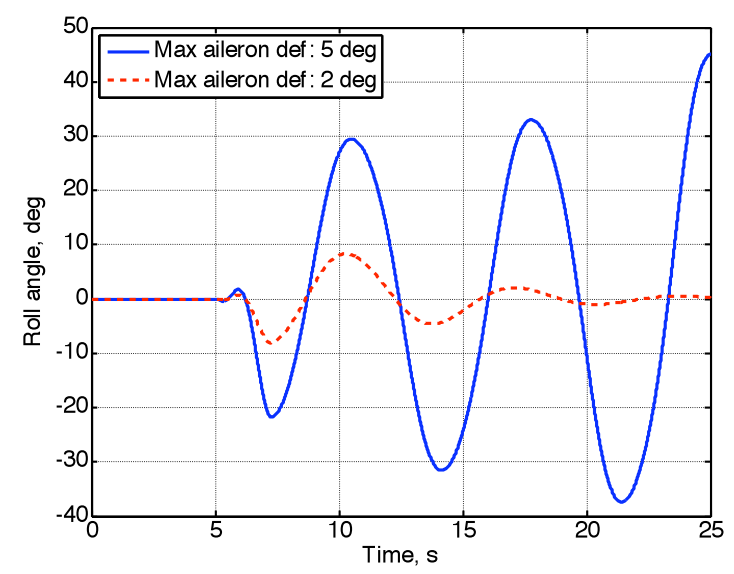

Figure 30. Change in the roll angle of the vehicle with different aileron inputs.

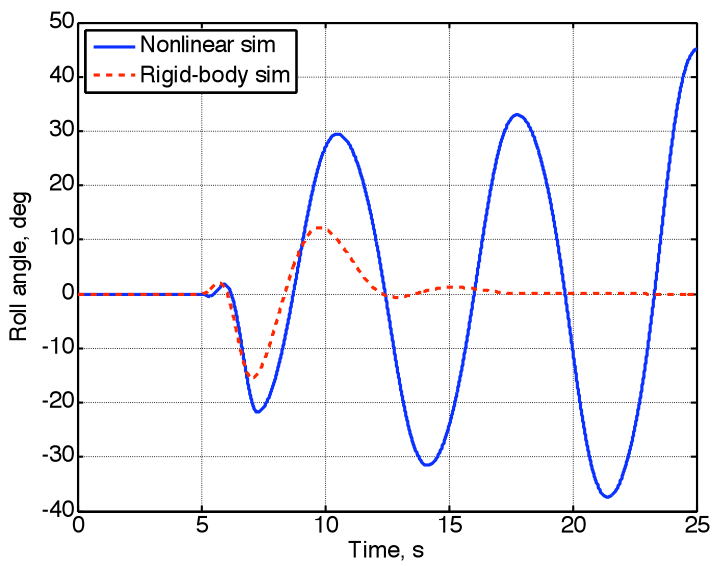

Figure 32. Roll angle from different simulations.

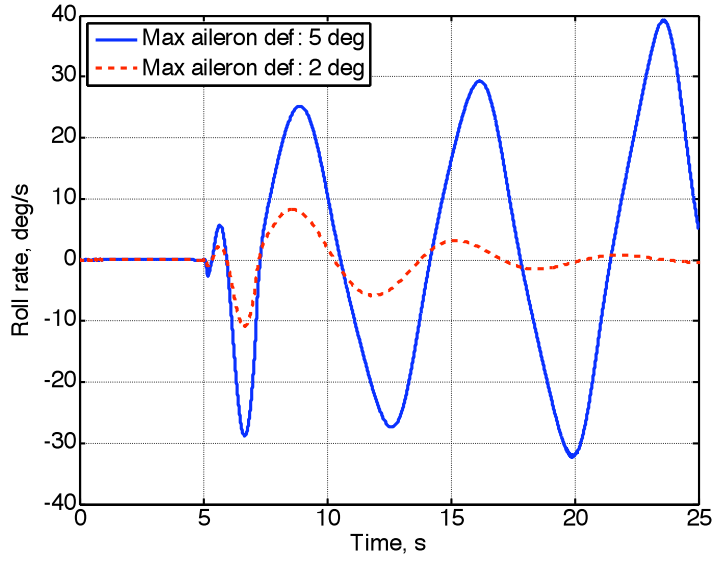

Figure 31. Change in the roll rate of the vehicle with different aileron inputs.

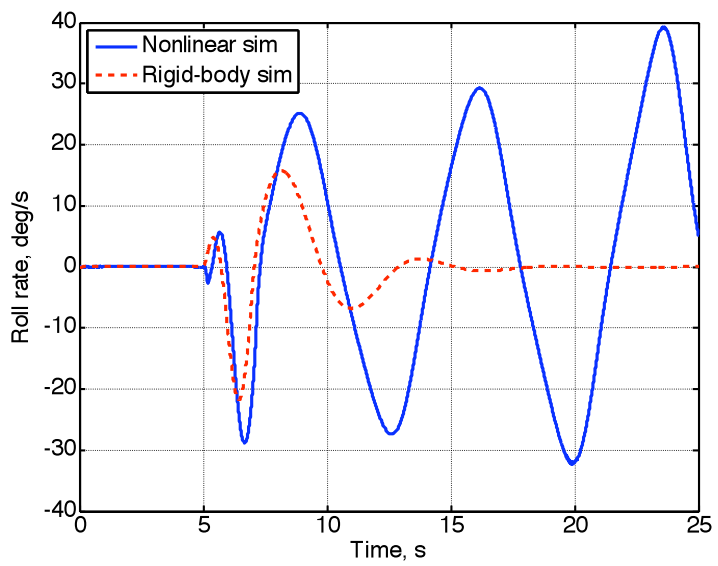

Figure 33. Roll rate from different simulations. 


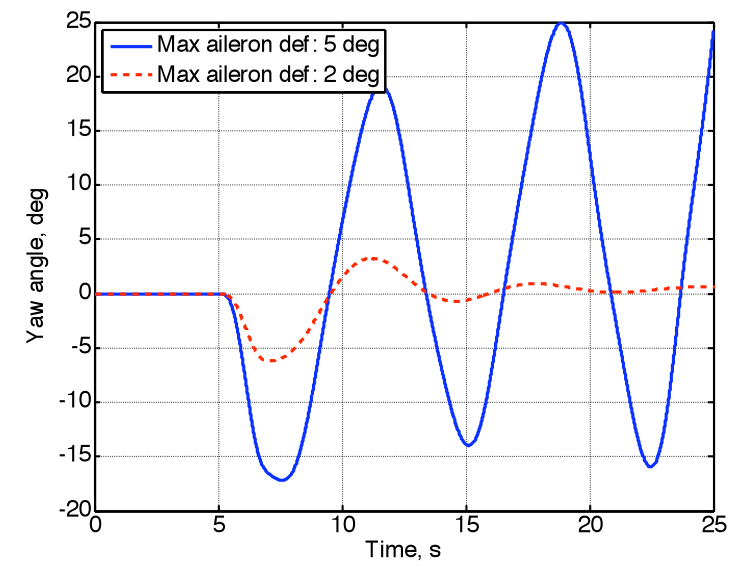

Figure 34. Change in the yaw angle of the vehicle with different aileron inputs.

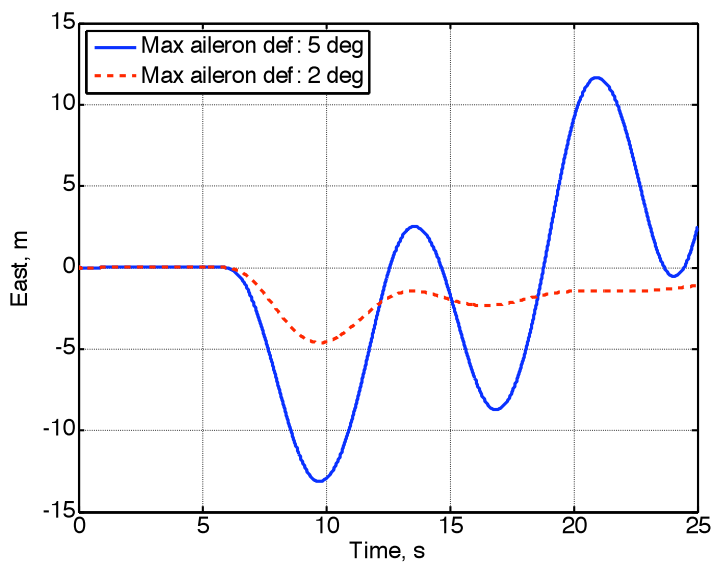

Figure 36. Change in the lateral position of the vehicle with different aileron inputs.

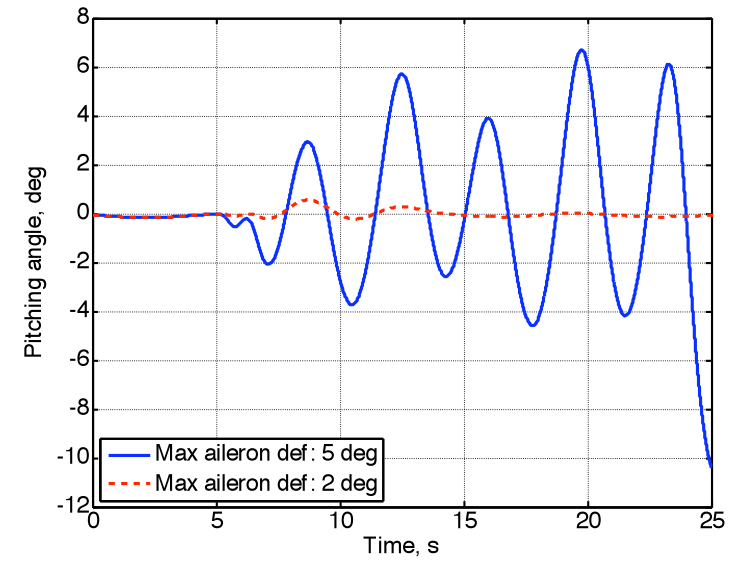

Figure 35. Change in the pitching angle of the vehicle with different aileron inputs.

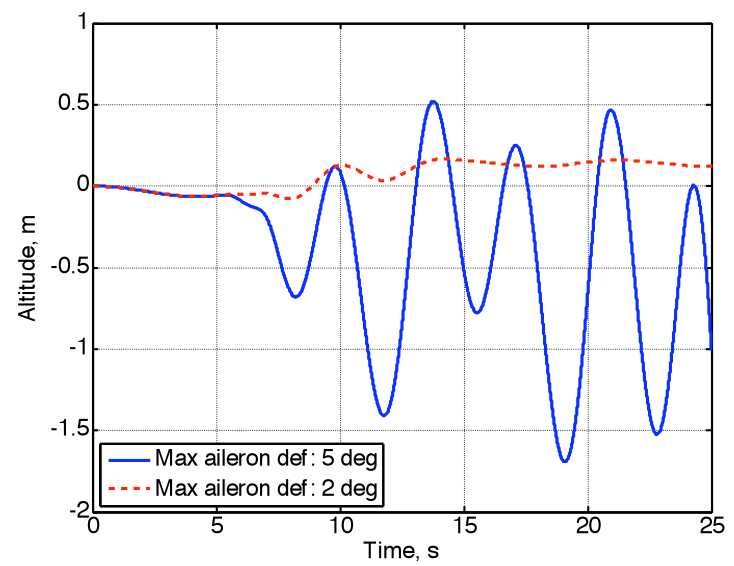

Figure 37. Change in the altitude of the vehicle with different aileron inputs.

Figure 38 shows the wing tip deflections due to the aileron input. It can be seen the additional wing tip deflection due to $2^{\circ}$ aileron input is relatively small, compared to the state at initial level flight. The magnitude of the bending oscillation is reduced with time, and the wing deformation is recovering to the steady state. However, for the simulation with $5^{\circ}$ aileron input, the wing deformation introduced by the aileron deflection is significantly larger, where the right wing tip deflection can exceed $42 \%$ of the half span. It is also clear that the bending oscillation of the wing is increased after the aileron actuation. Therefore, the $5^{\circ}$ aileron input case (under this frequency of $0.5 \mathrm{~Hz}$ ) can be seen as an upper limit for excitation during flight. While in this model the aileron was taken as a full section span (1-m long), in the actual X-HALE it will be no more than $25-\mathrm{cm}$ span. This will allow for an equivalent $20^{\circ}$ aileron input for similar vehicle response. Limits on the aileron deflections will be provided by software.

Table 9 lists the strain components in the material direction. Again, one can see the normal stain in the longitudinal direction exceeds $3000 \mu \varepsilon$. Figure 39 plots the spanwise and spatial distributions of the strain in this direction. The large strain happens after the aileron actuation. 


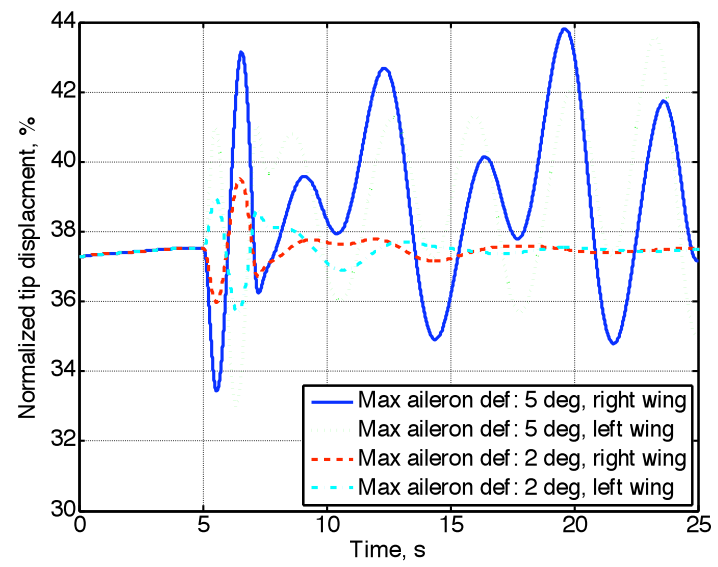

Figure 38. Normalized wing tip deflections.

Table 9. List of maximum and minimum strains with the $5^{\circ}$ aileron inputs

\begin{tabular}{lcc}
\hline \hline & Maximum $(\mu \varepsilon)$ & Minimum $(\mu \varepsilon)$ \\
\hline$\varepsilon_{11}$ & 2881.0 & -3499.2 \\
$\varepsilon_{12}$ & 587.9 & -478.4 \\
$\varepsilon_{13}$ & 708.7 & -576.7 \\
$\varepsilon_{22}$ & 1182.0 & -1024.5 \\
$\varepsilon_{23}$ & 758.8 & -756.8 \\
$\varepsilon_{33}$ & 752.7 & -516.5 \\
\hline \hline
\end{tabular}
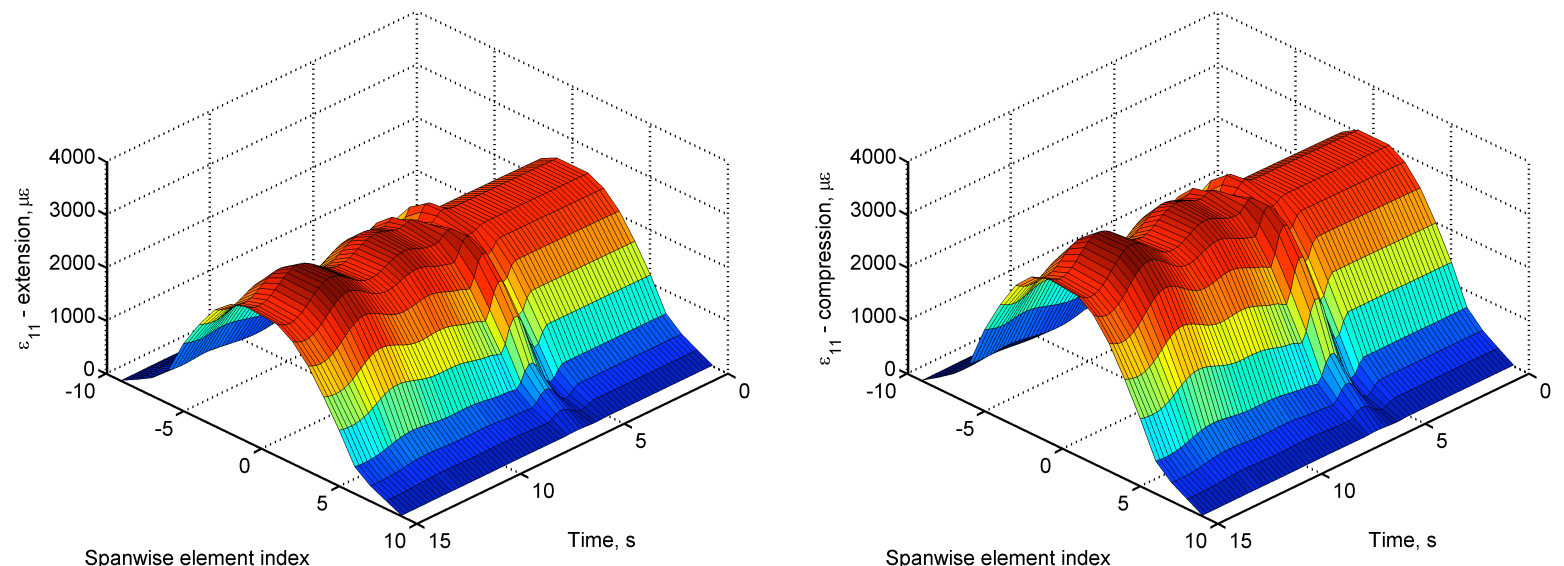

Figure 39. Normal strains in fiber longitudinal direction ( $\varepsilon_{11}$, left: extension; right, compression).

\section{Concluding Remarks}

This paper introduced the X-HALE UAV as a test bed for nonlinear aeroelastic flight tests. The 8-m span very flexible aircraft is expected to excite coupled nonlinear aeroelastic/flight dynamic coupled responses due to controlled excitation that will provide valuable data in support to code validation. The design and manufacturing processes chosen for the airframe were such that the elastic, inertial and geometric properties can be well characterized. The integrated airframe, on-board computers, controls, and software were presented. A network of strain gages and accelerometers provides measurements for the instantaneous deflection shape. Three 5-hole probes along the wingspan provide basic aerodynamic data. Engine thrust (through rpm measurement), control surface rotations, and center pod inertial measurements are also obtained during flight. Batteries provide power to the five 
electric motors for at least 45-minute flights, which will be enough to conduct several test matrix points. Manufacturing of the first flight test vehicle is underway, along with a series of bench tests to fully characterize various structures, aerodynamics, propulsion, electronics and software unique aspects of the X-HALE.

The expected X-HALE aeroelastic behavior was obtained using UM/NAST, a comprehensive preliminary aeroelastic design tool for very flexible aircraft. The design presents significant wing deflections under trimmed condition as desired. It also has the control authority to excite large dynamic responses and to even develop (controlled) aeroelastic instabilities. Due to the large deformation under trimmed condition, the safety margins left for the vehicle to sustain gust perturbations and maneuver has to be monitored closely, as the local normal strains could transiently exceed $3000 \mu \varepsilon$. From the simulation with anti-symmetric aileron actuations, the roll motion of the vehicle could go unstable. Moreover, complex 3-D rotational and translational motions were observed with the introduced aileron inputs, which indicate possible test point to be explored during flight tests and for which wind tunnel tests would not be feasible.

The first flight of the X-HALE flight test vehicle is expected to occur in June 2010. The goal for this first phase is to assess its handling qualities, its basic aeroelastic response, and how these correlate with UM/NAST predictions. From those, design changes are expected and a new airframe will then be finalize for the aeroelastic flight tests.

\section{Acknowledgments}

This work has been supported by the Air Force Research Laboratory under the Michigan/AFRL Collaborative Center in Aeronautical Sciences (MACCAS). The technical monitor is Dr. Gregory Brooks (AFRL/RBAA). Additional funds were also provided by the University of Michigan's Active Aeroelasticity and Structures Research Laboratory. Finally, the authors would like to thank the University of Michigan students who have been supporting the X-HALE development: Roy Blankman, Blake Davis, Daniel Ellis, Marc Lecerf, Kevin Gregus, Elizabeth Prentice, and Jonathan Wiebenga.

\section{References}

1. Tilmann, C. P., Flick, P. M., Martin, C. A., and Love, M. H., "High-Altitude Long Endurance Technologies for SensorCraft," RTO AVT Symposium on "Novel Vehicle Concepts and Emerging Vehicle Technologies," Brussels, Belgium, April 7-10 2003, MP-104-P-26-1.

2. Whitson, S., "The Proteus, Giving Shape to Forms Unknown," Private Pilot, Vol. 33, No. 12, December 1998, pp. 44-50.

3. Noll, T. E., Brown, J. M., Perez-Davis, M. E., Ishmael, S. D., Tiffany, G. C., and Gaier, M., "Investigation of the Helios Prototype Aircraft Mishap," Tech. Rep., NASA, January 2004.

4. Wilson, J. R., "Fly Like a Vulture," Aerospace America, Vol. 46, No. 11, November 2008, pp. 28-33.

5. RCAS User's Manual, Version 2.0, US Army Aviation and Missile Command, Moffett Field, CA

6. Drela, M., "Integrated Simulation Model for Preliminary Aerodynamic, Structural, and Control-Law Design of Aircraft," Proceedings of the $40^{\text {th }}$ AIAA/ASME/ASCE/AHS/ASC Structures, Structural Dynamics, and Materials Conference and Exhibit, St. Louis, Missouri, April 12-15 1999, pp. 1644-1656, AIAA Paper No. 991394.

7. Cesnik, C. E. S. and Brown, E. L., "Modeling of High Aspect Ratio Active Flexible Wings for Roll Control," Proceedings of the $43^{\text {rd }}$ AIAA/ASME/ASCE/AHS Structures, Structural Dynamics, and Materials Conferences, Denver, Colorado, April 22-25 2002, AIAA Paper No. 2002-1719.

8. Cesnik, C. E. S. and Su, W., "Nonlinear Aeroelastic Modeling and Analysis of Fully Flexible Aircraft," Proceedings of the $46^{\text {th }}$ AIAA/ASME/ASCE/AHS/ASC Structures, Structural Dynamics and Materials Conference, Austin, TX, April 18-21, 2005, AIAA Paper No. 2005-2169.

9. Shearer, C. M., Coupled Nonlinear Flight Dynamics, Aeroelasticity, and Control of Very Flexible Aircraft, Ph.D. thesis, The University of Michigan, Ann Arbor, MI, 2006, PhD Dissertation.

10. Shearer, C. M. and Cesnik, C. E. S., "Nonlinear Flight Dynamics of Very Flexible Aircraft," Journal of Aircraft, Vol. 44, No. 5, September - October 2007, pp. 1528-1545.

11. Shearer, C. M. and Cesnik, C. E. S., "Trajectory Control for Very Flexible Aircraft," Journal of Guidance, Control, and Dynamics, Vol. 31, No. 2, March-April 2008, pp. 340-357.

12. Patil, M. J., Hodges, D. H., and Cesnik, C. E. S., "Nonlinear Aeroelasticity and Flight Dynamics of HighAltitude Long-Endurance Aircraft," Journal of Aircraft, Vol. 38, No. 1, pp. 88-94, 2000. 
13. Patil, M. J. and Hodges, D. H., "Flight Dynamics of Highly Flexible Flying Wings," Journal of Aircraft, Vol. 43, No. 6, November-December 2006, pp. 1790-1798.

14. Chang, C. S., Hodges, D. H., and Patil, M. J., "Flight Dynamics of Highly Flexible Aircraft," Journal of Aircraft, Vol. 45, No. 2, March-April 2008, pp. 538-545.

15. Chandra, R. and Chopra, I., "Structural Response of Composite Beams and Blades with Elastic Couplings," Composite Engineering, Vol. 2, Nos. 5-7, 1992, pp. 347-374.

16. Minguet, P. and Dugundji, J., "Experiments and Analysis for Structurally Coupled Composite Blades Under Large Deflections. Part 1 - Static Behavior," Proceedings of the $30^{\text {th }}$ AIAA/ASME/ASCE/AHS/ASC Structures, Structural Dynamics, and Materials Conference, AIAA Paper No. 89-1365, 1989, pp. 1807-1816.

17. Minguet, P. and Dugundji, J., "Experiments and Analysis for Structurally Coupled Composite Blades Under Large Deflections. Part 2 - Dynamic Behavior," AIAA Journal, Vol. 28, No. 9, pp. 1580-1588, 1990.

18. Tang, D.M. and Dowell, E.H., "Experimental and Theoretical Study on Aeroelastic Response of High-aspectratio Wings," AIAA Journal, Vol. 39, No. 8, pp. 1430-1441, 2001.

19. Tang, D.M. and Dowell, E.H., "Experimental and Theoretical Study of Gust Response for High-aspect-ratio Wing," AIAA Journal, Vol. 40, No. 3, pp. 419-429, 2002.

20. Palacios, R., Cesnik, C. E. S., and Reichenbach, E., "A Re-examination of the Structural Design Procedures for Very Flexible Aircraft," Proceedings of the International Forum on Aeroelasticity and Structural Dynamics, Stockholm, Sweden, June 18-21, 2007.

21.Su, W. and Cesnik, C.E.S., "Dynamic Response of Highly Flexible Flying Wings," Proceedings of the $47^{\text {th }}$ AIAA/ASME/ASCE/AHS/ASC Structural, Structural Dynamics and Materials Conference, Newport, Rhode Island, 2006.

22. Cesnik, C.E.S. and Brown, E.L., "Active Warping Control of a Joined Wing Airplane Configuration," Proceedings of the $44^{\text {th }}$ AIAA/ASME/ASCE/AHS/ASC Structures, Structural Dynamics, and Material Conference, Hampton, Virginia, 2003.

23. Brown, E.L., "Integrated Strain Actuation in Aircraft with Highly Flexible Composite Wings," Ph.D. Thesis, Mechanical Engineering, Massachusetts Institute of Technology, Cambridge, Massachusetts, 2003.

24. Cesnik, C.E.S. and Ortega-Morales, M., "Active Aeroelastic Tailoring of Slender Flexible Wings," Proceedings of the International Forum on Aeroelasticity and Structural Dynamics, Madrid, Spain, 2001.

25. Van Schoor, M.C. and von Flotow, A.H., "Aeroelastic Characteristics of a Highly Flexible Aircraft," Journal of Aircraft, Vol. 27, No. 10, pp. 901-908, 1990.

26. Jones, R.I., "The Design Challenge of High Altitude Long Endurance (Hale) Unmanned Aircraft," The Aeronautical Journal, pp. 273-280, 1999.

27. Jones, R.I., "Selection and Comparison of Unmanned Aircraft Configurations," In $12^{\text {th }}$ RPVs International Conference, Bristol, United Kingdom, Sept. 9-11, 1996, Conference Papers (A97-21501 04-01), Bristol, United Kingdom, University of Bristol, 1996. 